\title{
Fotografia e História: ensaio bibliográfico
}

\author{
vânia Carneiro de Carvalho \\ Museu Paulista/Universidade de São Paulo \\ Solange Ferraz de Lima \\ Museu Paulista/Universidade de São Paulo \\ Maria Cristina Rabelo de Carvalho \\ Historiadora \\ Tânia Francisco Rodrigues \\ Instituto Cultural Itaú
}

1. Um quadro de tendências do uso da fotografia na cidade de São Paulo, incluindo-se uma sinalização da produção crítica e acadêmica, especialmente nos anos 80 , pode ser encontrado no livro Fotografia, de Mônica Junqueira de Camargo e Ricardo Mendes, publicado pelo Centro Cultural São Paulo em 1992.

2. Foram localizadas apenas cinco obras de caráter bibliográfico, sendo que uma delas não foi publicada, tendo sido produzida como material de apoio (FUNARTE. Fotografia: material de apoio aos seminários sobre arquivo fotográfico. Rio de Janeiro, FUNARTE, 1981, 7p.ms). Os levantamentos publicados pela FUNARTE e pelo Museu Lasar Segall são referências importantes mas, hoje, desatualizadas pois datam da década de 70 e início de 80 (FUNARTE. Foto-

Um caminho possivel e, com certeza, útil, teria sido "inventariar" os núcleos fotográficos hoje disponíveis no Brasil, para, deste modo, servir como uma espécie de guia panorâmico aos pesquisadores e interessados neste tipo de documento ${ }^{3}$. A preocupação com a produção de catálogos e coletâneas 
grafia: levantamento bibliográfico. Rio de Janeiro, FUNARTE, 1981, 70p; MUSEU LASAR SEGALL. Bibliografia Fotografia 2. São Paulo, Museu Lasar Segall, 1978. (2.ed. aumentada em 1981); MUSEU LASAR SEGALL. Bibliografia - Fotografia. São Paulo, Museu Lasar Segall, 1976, 31p.).A Bibliografia produzida pelo Centro de Memória da Unicamp é a mais recente, apresentando recortes temáticos específicos e identificados, porém circunscrevendo-se ao acervo da Biblioteca do Centro (C.M.U. Bibliografia Temática. Boletim do Centro de Memória da UNICAMP, v.5, n.10, jul.dez. 1993, p.131-142).

3. A única referencia encontrada e que guarda o caráter de guia geral, ainda que em um artigo, data de 1982 e diz respeito aos arquivos fotográficos da cidade do Rio de Janeiro (MURAKAMI, Ana Maria Brandão et alii. Cadastro de arquivos fotográficos existentes na cidade do Rio de Janeiro, em instituições privadas, governamentais e particulares. Arquivo fotográfico. Estudo preliminar. Rio de Janeiro, Funarte, 1982.). As demais referências são catálogos de acervos fotográficos, portanto, dizem respeito a uma única instituição à qual pertencem os documentos elencados. Existe ainda uma série de artigos e comunicações produzida por pesqui- institucionais e particulares, bem como com o tratamento físico das coleções fotográficas tem revertido em avanços visiveis. Entretanto, o trato direto com estas coleções nos privaria de fazer uma avaliação do uso documental que se fez da fotografia.

Deste modo, nosso interesse incidiu não sobre a fotografia propriamente, mas sobre as obras de autoria nacional que fizeram uso da fotografia numa perspectiva histórica. Este recorte, necessário, primeiramente, para viabilizar uma análise nos limites de um ensaio, permite que sejam apresentados os problemas de natureza epistemológica e cultural tradicionalmente associados à documentação fotográfica, como os conceitos de memória, passado, história, testemunho, realidade sensivel, representação visual, etc., e que são recorrentes nestes vários tipos de estudos.

Longe de esgotar as reflexões enunciadas acima, este ensaio tem como objetivo instrumentalizar o pesquisador em uma faixa mais especializada de problemas teóricos e metodológicos relacionados à pesquisa histórica com fontes fotográficas. Este caráter de ferramenta está presente na nossa opção por uma abordagem com ênfase descritiva dos conjuntos de obras, que culmina na apresentação da listagem bibliográfica ${ }^{4}$, acompanhada por uma múltipla categorização de cada obra, conforme uma tipologia sumária ${ }^{5}$.

A opção pelo formato ensaio, e não pelo balanço, se justifica pela dificuldade em cobrir toda a bibliografia produzida em território nacional sobre o tema fotografia e históriá. Assim, a relação de obras aqui apresentada pode ser considerada representativa, mas não exaustiva. A disponibilidade em instituições públicas acabou sendo um outro critério necessário. São raras as referências, em cadastros bibliográficos, a obras de proprietários particulares.

O levantamento foi realizado a partir das cidades de São Paulo e Rio de Janeiro, consultando-se basicamente os cadastros de livros, periódicos e teses das universidades estaduais e particulares de São Paulo e Rio de Janeiro, das universidades federais e instituições culturais públicas e privadas detentoras de documentação fotográfica ou com biblioteca sobre o assunto ${ }^{7}$. A bibliografia referenciada em cada uma das obras consultadas nos serviu como meio de controle, já que pudemos perceber o quanto estávamos esgotando o universo existente.

Uma primeira sondagem dos títulos arrolados já mostra ao leitor a grande diversidade de uma produção bibliográfica que utiliza a fotografia como fonte para o conhecimento de fenômenos passados, sejam estes ligados à história social, história da visualidade, história do cotidiano, história urbana, história do próprio suporte fotográfico, da atividade de seus profissionais, histórias internas de personalidades, grupos étnicos, profissionais, empresariais, politicos, etc.

\section{Categorias Temáticas}

Após a análise da primeira amostragem do levantamento dividiu-se o conjunto bibliográfico em cinco calegorias básicas, através das quais foi 
possivel caracterizar as obras, bem como otimizar as leituras e as análises comparativas.

$\bigcirc$ primeiro conjunto (repertório documental) circunscreve obras com preocupações marcadamente documentárias. Aqui o tratamento da fotografia é muito mais empírico. Ela aparece como unidade documental que necessita de coerência dentro do conjunto no qual se insere, de identificação e de contextualização. Trata-se de fac-similes, reproduzindo publicações ou álbuns fotográficos do século passado; de obras que apresentam e divulgam imagens de coleções particulares ou institucionais, sejam estas de caráter temático ou biográfico e de edições retrospectivas de ensaios fotográficos.

Acompanhando o viés empírico presente no primeiro recorte - o tipo documentário - define-se um segundo conjunto (processamento técnico), no qual a fotografia é vista como unidade documental passivel de tratamento técnico especializado. Trata-se de obras que apresentam propostas ou experiências de processamento catalográfico ou arquivístico, de formas de acondicionamento físico, de conservação, de restauração, ou de organização de cadastros informatizados e de bancos de dados.

Em uma posição intermediária entre o tratamento empírico-descritivo e a abordagem analítica situa-se o terceiro conjunto (história da fotografia), que trata da trajetória temporal e espacial dos diferentes suportes fotográficos. Nesta perspectiva incluem-se as obras que apresentam históricos parciais da produção fotográfica no país, como aqueles da constituição dos primeiros ateliês no século XIX, ou relativos aos fenômenos do fotojornalismo, da cartofilia, do lambe-lambe, etc. Fazem também parte deste conjunto as obras que vinculam a atuação de determinados fotógrafos, personalidades ou instituições ao desenvolvimento da fotografia.

Diferentemente, o quarto e o quinto conjuntos se afastam, em graus diversos, do tratamento empírico para adentrar o campo teórico e analítico. $\bigcirc$ quarto conjunto de obras (teoria e metodologia) aborda diretamente o tema sob o prisma conceitual e metodológico, desenvolvendo reflexões sobre a significação da imagem fotográfica, sobre a natureza e constituição da sua linguagem e sobre as especificidades da fotografia como fonte para a pesquisa histórica.

quinto e último conjunto (significação histórica) reúne obras que, apesar de apresentarem procedimentos tanto de ordem documental quanto conceitual, diferenciam-se dos demais por efetivamente utilizar a fotografia como fonte de pesquisa para o conhecimento dos processos sociais de construção de sentidos. À fotografia são atribuídas funções sociais estruturantes. A história da fotografia se transforma aqui em história da visualidade ${ }^{8}$.

Por fim, em um número significativo de obras percebemos a utilização da fotografia não contemporânea como instrumento de reforço, complementação ou ilustração da narrativa, que se desenvolve à revelia da imagem. Estas obras, fartamente ilustradas, dificilmente formariam um conjunto coerente já que não se orientam pela documentação fotográfica e não apresentam uma cobertura sistemática, seja de um acervo fotográfico, seja de um tema. Entretanto, já que se trata de um uso recorrente da fotografia histórica elas estão citadas, porém apenas de maneira exemplar, guardando, desta sadores e técnicos, que apresentam o seu local de atuação.

4. Foram mantidos os títulos de obras que não puderam ser consultadas, mas sobre as quais foi possivel obter informaçòes suficientes para incluí-las no recorte temático proposto. Estas obras estão na listagem com a fonte bibliográfica citada.

5. É importante deixar claro que não há, nesta classificação, nenhum objetivo hierarquizante ou constitutivo de classes estanques. Nossa intenção é unicamente operacional, ou seja, trabalhar com as obras dentro de um quadro tipológico foi a maneira mais eficiente de caracterizar o seu conteúdo e tratar dos principais problemas por elas suscitados. A classificaçào indicada ao final de cada referência bibliográfica apenas explicita o nosso método de trabalho e permite que sejam recuperados os conjuntos tratados, inclusive numericamente.

6. Apesar da extensão alcançada pelo levantamento, centros como Recife e Salvador, além dos estados do sul mereceriam um novo investimento.

7. Além das instituições consultadas e/ou responsáveis por algumas das publicaçōes citadas, cujos nomes encontram-se ao final deste ensaio, o levantamento foi realizado nas seguintes bases de dados e catálogos: UNIBIBLI-CDRom (USP, UNESP, UNICAMP). Catálogo coletivo de 
livros, teses e publicaçōes seriadas. 2.ed. São Paulo, Sistemas de Bibliotecas Universidades Estaduais Paulistas/ FAPESP/BIREME, 1995; USP-CDRom. Catālogo da produção técnico-científica e artística do corpo docente/pesquisadores e teses da USP. Edição Preliminar, São Paulo, USP/SIBi, 1995; Banco de Dados Bibliográficos sobre Fotografia produzido pela Equipe Técnica de Pesquisas em fotografia $\mathrm{da}$ Divisão de Pesquisas do Centro Cultural São Paulo; ANPUH. Produçâo bistoriográfica brasileira, 1985-1994. São Paulo, ANPUH, 1995; Banco Informatizado da Produção Docente da Escola de Comunicações e Artes da USP; $\mathrm{CFCH} / \mathrm{UFRJ}$. Theoroi. Catálogo de teses e dissertações em filosofia $e$ ciências bumanas. Base de dados dos investigadores da cultura. Rio de Janeiro, Universidade Federal do Rio de Janeiro/ Centro de Filosofia $e$ Ciências Humanas/ Biblioteca Central, 1993. 8. As funções exercidas e os sentidos produzidos pela sociedade dizem respeito a um universo mais amplo que envolve o consumo de outros suportes visuais além da fotografia. Estas práticas sociais - publicitárias, pedagógicas, comemorativas, políticas, etc.- extrapolam o momento da produção material da imagem ou a sua evolução técnica. forma, um caráter de amostragem - histórias de cidades e de bairros, histórias institucionais e empresariais, histórias de personalidades, de eventos, de grupos sociais, histórias enciclopédicas, etc. (ver ao final do artigo nota bibliográfica em anexol

\section{A Fotografia e os Repertórios Documentais (RD)}

Este conjunto é o mais numeroso, contendo 148 obras de um universo de 395. A divulgação de coleções está, sem dúvida, associada a entidades detentoras de acervos fotográticos. Se dividirmos os editores entre instituições públicas, privadas, fundações (sociedades ou organizações de classe) e as editoras propriamente ditas, poderemos perceber que $42 \%$ das edições deste tipo estão a cargo de órgãos públicos, entre eles prefeituras e universidades. As fundações só adquirem expressividade numérica a partir da iniciativa do Instituto Cultural Itaú em publicar pequenos repertórios urbanos. Das publicações de repertórios documentais, $20 \%$ são fruto da iniciativa privada, dentre as quais se destacam aquelas custeadas por empresas de construção civil ou obras públicas e 19,5\% foram custeadas por editoras. As cidades de São Paulo, com 82 edições, e Rio de Janeiro, com 43, lideram as publicações documentais, isso não apenas porque os temas ou coleções são de origem paulista ou carioca, mas pela condição de eixo comercial e financeiro que preenchem.

De 18 livros publicados entre 1950 e 1970, há um salto para 74 unidades na década seguinte. Os anos 80 conhecem um boom de publicações documentais, cujo número se mantém estável nos anos 90 . Há uma nítida preferência pela produção fotográfica do século XIX ou por um recorte que, incluindo o século XIX, se estenda até meados da década de 1920 . Cronologias amplas, que apresentam, por amostragem, uma imagem de cada ano sobre o tema tratado também têm um número expressivo, ficando em segundo plano aquelas que se dedicam a períodos mais recentes como as décadas de 1940 a 1960.

O tema por excelência destes repertórios é a cidade, $49 \%$ dos livros publicados reúnem imagens cujo eixo organizador é o espaço urbano. Em seguida, com $25 \%$ do conjunto, encontramos os repertórios de coleções. $O$ restante está distribuído entre temas como retrato, estrada de ferro, arquitetura, carnaval, automóvel, etc.

Várias podem ser as razões que concorreram para um número tão elevado de publicações sobre a cidade. A produção de retratos foi, tradicionalmente, o "ganha-pão" dos estúdios fotográficos. As qualidades mundanas e comerciais do retrato o deixaram de fora das experimentações dos fotógrafos, que, quando interessados em ingressar no meio considerado artístico, tratavam de procurar na paisagem urbana, ou mesmo rural, a devida fonte de inspiração.

A intensa transformação que as cidades conhecem e, simultaneamente, a prática de documentá-las através da fotografia para fins políticos ou administrativos certamente concorreram para a geração de arquivos fotográficos sobre a temática urbana. 
Por fim, a cidade tem se destacado, há um longo tempo, como um tema de importância em várias disciplinas como arquitetura, urbanismo, sociologia, etc., muito antes da fotografia, ela mesma, conquistar espaços nas universidades como fonte de pesquisa.

No meio acadêmico, o interesse pela fotografia, especialmente pelas informações complementares que esta pode trazer para os estudos da evolução urbana, serviu de alavanca para a organização e divulgação de acervos, hoje parcialmente acessíveis ${ }^{9}$. Em São Paulo, muitas das coletâneas e fac-similes sobre a cidade contam com análise e organização documental realizadas por arquitetos das áreas de história urbana ou da arquitetura ${ }^{10}$.

Os repertórios documentais urbanos são muito antigos. Um dos pioneiros neste tipo de edição foi o fotógrafo Militão Augusło de Azevedo, que lança, em 1887, o seu Álbum Comparativo da Cidade de São Paulo, 1862 1887. Desde então, a prática de comparar diversos momentos da cidade tornou-se uma fórmula consagrada de apresentação de repertórios fotográficos urbanos no mercado editorial, incluindo-se nesse contexto as publicações produzidas por órgãos públicos para divulgar os empreendimentos urbanos de seus governos ${ }^{11}$.

Utilizando-se de pouquíssimo texto, à exceção de legendas de identificação espacial, estes álbuns narram o processo de crescimento urbano de forma linear, destacando os aspectos modernizantes da mudança. $\bigcirc$ antigo é incorporado como fase anterior de um único processo de desenvolvimento. Este tipo de álbum parece constituir um contrapeso, com conotações altamente positivas, para a desestruturação espacial e possivelmente emocional, que acompanha qualquer fenômeno acelerado de alteração física da cidade no contexto socialmente marginalizante do sistema capitalista. Não é por acaso que a apresentação de imagens do passado é quase sempre associada à intenção de conservar a memória. Entretanto, apesar da maioria destas imagens estar inserida em um processo intensamente dinâmico, como o das transformações urbanas, o fenômeno da memória é, ao contrário, tratado de forma estanque, imutável, quase absoluta.

O termo memória está presente na maioria das publicações deste conjunto, apresentando, no entanto, conotações diversas. Por vezes a memória é tratada como uma categoria abstrata e vem associada a termos como conservação, recuperação, resgate, preservação, pressupondo a existência de um registro mental coletivo da realidade passada que se considera passível de ser recuperado através da reunião e divulgação impressa de fotografias antigas.

Os termos memória visual e memória fotográfica são utilizados de forma a justificar a divulgação de acervos institucionais e privados, e, via de regra, a eles é atribuído o poder de reconstituição da história. Neste caso, o termo memória é entendido como equivalente a um conjunto de documentos, tendo, assim, uma materialidade. Este binômio memória/reconstituição histórica, tal como vem sendo formulado no que se refere à documentação fotográfica, desconsidera os sentidos presentes nas mediações, seja dos produtores primeiros das imagens (fotógrafo, editor, arranjador, etc), seja de seus consumidores, ou ainda daqueles que retomaram esta documentação para lançar, a seu modo, uma coletânea de documentos fotográficos. Temos aí
9. Vale lembrar que esta funçào documental da arquitetura não se restringe aos suportes fotográficos e já mobilizou outros suportes iconográficos. Integrando o movimento de recuperação do estilo colonial brasileiro, ocorrido na segunda década deste século, o arquiteto Ricardo Severo desenvolveu, juntamente com o pintor e desenhista Wasth Rodrigues, um projeto de reprodução iconog̀ráfica de igrejas e edificios coloniais dos séculos passados percorrendo várias cidades do Brasil. Neste caso, é possivel que a fotografia tenha sido mobilizada na coleta dos registros necessários ( $\mathrm{Cf}$. José Wasth Rodirigues. Documentârio Arquitetônico. São Paulo, Martins Fontes, 1944. Há outra edição, lançada pela Edusp/SP, de 1979). De qualquer modo, a relação entre fotografia e arquitetura remonta já ao início da trajetória da atividade fotográfica (Cf. Carvalho \& Wolff, 1991: 131-172). 10. Benedito Lima de Toledo, Carlos Lemos, Nestor Goulart Reis Filho, Mônica Junqueira de Camargo, Maria Cristina Wolff de Carvalho, Silvia Ferreira Santos Wolff, etc., sem contar aqueles que, com formação em arquitetura, se voltaram para o campo da fotografia, como Boris Kossoy, Ricardo Mendes, Helouise Costa, Paulo Cezar Alves Goulart, apenas para citar alguns. 
11. Os álbuns comparativos que foram localizados constam na listagem ao final do texto.

12. Marcos Tamoyo, então prefeito da cidade do Rio de Janeiro, assim apresenta um dos inúmeros livros de Gilberto Ferrez: "Para contar de forma simples e resumida a história da praça mais importante do Brasil, o notável pesquisador Gilberto Ferrez usou seu método tão eficiente e tão agradável para os leitores narrando os fatos e ao mesmo tempo mostrando os aspectos da época." (Ferrez, 1978:7)

13. A proposta do "living museum" é justamente reconstituir situaçōes passadas com personagens que agem como se estivessem em uma segunda realidade. Aplicado a exposiçòes, este tipo de procedimento pretende se contrapor ao assim considerado "museu tradicional". Cf. Ulpiano T. Bezerra de Meneses. Do Teatro Da Memória ao Laboratório da História. A Exposição Museológica e o Conhecimento Histórico. Anais do Museu Paulista. História e Cultura Material. Nova série, v.2, 1994.

14. Ulpiano T. Bezerra de Meneses, op. cit. 15. Na apresentaçào do Album de Pbotograpbias do Estado de São Paulo 1892 a importância da obra é ressaltada, principalmente, por permitir o confronto dos locais fotografados no passado com o momento pre- arraigada a idéia de que o documento, por si só, contém a história e que, portanto, a sua mera divulgação já seria suficiente para trazêtla à luz ${ }^{12}$.

Preservação e resgate também aparecem relacionados à idéia de passado. Contraditoriamente, pretende-se que a imagem fotográfica, ao "representar o instante", seja capaz de recuperar a experiência do tempo, que é contínuo, não seletivo, ininterrupto $e$, antes de tudo, irretornável (Neiva, 1986:65). A crença no "túnel do tempo" conhece um exemplo radical e, por isso, elucidativo, na experiência dos "living museums"13, que pretende reconduzir ao presente uma situação já vivida, reificando o passado, abolindo as distâncias temporais $e$, assim, a percepção da alteridade. A compreensão da fotografia como uma versão "envelhecida" do presente anula a possibilidade do conhecimento histórico, o qual necessariamente se constrói sobre o estranhamento ${ }^{14}$.

O caráter ideológico do que nos parece um conceito decorrente do "senso comum" pode ser observado, por exemplo, na apresentação das publicações patrocinadas pela Companhia Brasileira de Projetos e Obras |CBPO|, onde a empresa esclarece que a preservação e a divulgação do passado é o eixo de seu programa editorial e que isto se concretiza através da edição de obras iconográficas (Kossoy, 1984, 1988). Nestes casos, é interessante notar que a referência à preservação do passado urbano diz respeito não à preservação de fato de estruturas urbanas ou arquitetônicas históricas e sim à sua imagem no registro fotográfico. Registro este que serve, inclusive, para suscitar espanto no leitor frente às mudanças ocorridas, que podem ser atestadas como índice de progresso ${ }^{15}$.

O viés da reconstituição pode também ser observado no tratamento descritivo e contextualizador que é a tônica destas coletâneas, que estão voltadas para a identificação dos logradouros, das cronologias e para a montagem da trajetória biográfica de seus fotógrafos. Na maioria das vezes, as imagens são deixadas à sua própria sorte, esperando-se que de sua "força" expressiva possam ser extraídas lições de fácil assimilação. Assim comenta Gilberto Ferrez as fotografias feitas por Marc Ferrez para a Comissão Geológica do Brasil: "(..) as mais notáveis (fotografias) estão aqui reproduzidas e falam por si." (Ferrez, 1989: 14)

Aqui está implícita também uma outra característica recorrente, ou seja, o gosto pela imagem de exceção. É interessante notar que justamente a respeito de um tipo de suporte que se destaca pela difusão maciça de imagens, busca-se ressaltar a imagem única, fundante ${ }^{16}$, ou "notável".

Ao contrário dos catálogos de acervos fotográficos publicados pelas instituições detentoras dos documentos ou de coletâneas como a do fotógrafo Christiano Júnior, que apresenta a totalidade de sua produção de retratos de escravos, reproduzida a partir de cinco acervos distintos, tanto público quanto privado, a recuperação de séries completas ou representativas da produção de totógrafos, que seria de grande valia para a pesquisa, não tem sido prioridade na maioria das montagens de repertórios ${ }^{17}$.

Outra característica importante das coletâneas reside na associação entre imagem fotográfica e realidade física da cidade. Em seu livro sobre Recife, Giberto Ferrez indica, para cada imagem, em uma pequena planta, o 
campo de visão do fotógrafo e o local aproximado de onde a fotografia teria sido feita. Além das âncoras espaciais acionadas por meio de plantas e de descrições minuciosas presentes nas legendas e nos textos históricos, o contato com aquilo que se pretende como "realidade passada" se daria através do fascínio de imagens que "revelam harmonia e perfeição estética"18.

A abordagem iconográfica empreendida por Kossoy nas duas publicações patrocinadas pela CBPO, acima referidas, não foge à regra. Cada imagem é acompanhada de um texto que detalha o conteúdo, fornecendo datas e históricos dos logradouros ou edifícios públicos registrados. Detém-se, também, nos aspectos concernentes à produção da imagem, como o ponto de vista do fotógrafo, o enquadramento, nitidez, etc. As introduções dessas publicações, no entanto, diferem das demais pelo rigor na contextualização da trajetória da fotografia no Brasil e de seus fotógrafos mais representativos, além de fornecer um panorama da evolução urbana de São Paulo na virada do século. O autor preocupa-se com a explicitação dos critérios e da metodologia adotados, expondo claramente os conceitos com os quais trabalhou e os encaminhamentos adotados na análise a que procede das imagens selecionadas $^{19}$.

Não se trata aqui de fazer uma crítica ao esforço de identificação e contextualização do documento fotográfico, prática indiscutivelmente necessária para a utilização de qualquer documento, mas de marcar os limites tênues entre o trabalho de documentação e uma concepção positivista da história.

Finalmente, não seria exagero afirmar que estas publicações "preservam" o potencial de encantamento das fotografias históricas através de altos investimentos na produção editorial, que garantem reproduções, na maioria das vezes, de excelente qualidade, em papel nobre, protegidas por capa dura e luxuosa, seguindo o padrão dos assim conhecidos "livros de arte", que se oferecem à fruição em salas de visita e de espera de grandes empresas, cujo prestígio se reflete nos tesouros históricos "descobertos" e na riqueza material de sua divulgação.

\section{A Fotografia e o seu Processamento Técnico (PT)}

Este conjunto reúne 39 referências bibliográficas, entre as quais $50 \%$ são artigos e $45 \%$ pequenas publicações avulsas (livretos). A grande maioria foi produzida e financiada por instituições públicas, entre as quais estão a Funarte, - Museu da Imagem e do Som/SP, o Centro de Pesquisa e Documentação da Fundação Getúlio Vargas (CPDOC-FGV) e o Arquivo Nacional. Também nesta área a década de 1980 concentra mais da metade das publicações, apontando este período como o início de uma confluência de interesses em relação à fotografia.

Observa-se, neste perfil, a ausência de obras de grande abrangência, que reúnam as opções existentes para o tratamento documental, conservação e preservação. Não existe também nenhuma publicação que contemple, no seu conjunto, as diferentes técnicas folográticas, suas formas de identificação, sintomas de deterioração e estratégias de conservação e sente e é atribuído um "fundo profético" ao colecionador que organizou a série fotográfica na virada do século, por ele ter selecionado aquelas imagens a partir das quais se pressente $o$ desenvolvimento que está por vir. Já no caso da publicaçào relativa à obra de Guilherme Gaensly - São Paulo, 1900- a sua atividade fotográfica é exaltada na medida de "...seu agudíssimo sentido de previsão do caminhamento da civilização aỏs lugares fotografados." (s.p.) 16. No livro de Pedro Vasquez, Niterói e a Fotografia: 1858-1958, é possivel identificarmos com clareza esta preocupação em apresentar imagens de uma época reconhecida $\mathrm{Co}$ mo fundante da cidade. A coletânea procura apresentar, a partir de uma série de fotógrafos e desenhistas, a primeira imagem que cada um teria feito da cidade de Niterói: A preocupação com o ineditismo integra tambêm os critérios de seleção para a publicação das 71 fotografias do Album de Pbotographias de São Paulo - 1892. Boris Kossoy, autor da publicação, esclarece que as 71 fotografias foram escolhidas de um conjunto original de 91 imagens por serem “...realmente representativas, parte das quais ainda inédita..." (p.11). A representatividade, no caso, justifica-se por serem estas imagens "...testemunhos visuais do periodo em que se altera sua feição (de São Paulo) colonial..." (p11). 
17. Ressalva deve ser feita às coletâneas produzidas pelo Instituto Cultural Itaú, que por serem de natureza pedagógica não poderiam obedecer às exigências de uma cobertura sistemática.

18. Gilberto Ferrez sobre as fotografias de Mulock em Babia, Velhas Fotografias 18581900, p.13.

19. Ver mais adiante 0 ítem A Fotografia como Significação Histórica. 20. O Thesaurus para Acervos Museológicos (Helena Dodd Ferrez e Maria Helena S. Bianchini, editado pelo SPHAN/Minc, 1987) classifica a fotografia na classe Comunicação, subclasse Documento. Esta subclasse, que reúne documentos textuais, cartográficos e iconográficos, foi aberta, segundo as autoras, para os casos de museus que não possuem arquivos ou bibliotecas (Cf. v.2, p.231). A fotografia (processo positivo direto) é referenciada, neste caso, apenas quanto ao seu suporte material (ambrótipo, daguerreótipo, ferrótipo). Termos identificadores do conteúdo iconográfico constam somente na classe Ar tes Visuais/Cinematografia, sub-classes Desenho, Escultura e pintura.

260 tratamento. A maioria dos trabalhos relata experiências pontuais de técnicos e pesquisadores com os acervos das instituições onde exercem sua atividade, sendo que parte deles se preocupa em apresentar a política de acervo adotada - opções temáticas, cronológicas e formas de coleta. Esses relatos, apresentados de maneira didática, descrevem os procedimentos básicos, quase profiláticos relacionados à manutenção física de fotografias - limpeza, embalagem, mobiliário, fichas técnicas, controles de localização, formas de acesso, etc.

Nota-se também a ausência de trabalhos que se dediquem ao desenvolvimento de vocabulários controlados que possam cobrir o grande espectro temático e cronológico dos acervos atuais ${ }^{20}$. O que se observa é a iniciativa isolada de cada instituição no desenvolvimento artesanal e empírico de descritores e listagens de assuntos, ou a tentativa de adaptar instrumentos de acesso múltiplo internacionais ou produzidos a partir de outras tipologias iconográficas.

Estes trabathos revelam uma ausência quase absoluta de descritores formais, ou seja, de uma terminologia que permita a identificação de atributos próprios da linguagem fotográfica - desde aspectos relativos ao modo de composição dos motivos até aspectos de enquadramento, ponto de visła, níveis de abrangência espacial, direções predominantes, etc. Alguns trabalhos acadêmicos, voltados para a análise de fenômenos históricos específicos, apresentam tentativas neste sentido (Essus, 1990; Carvalho, 1995; Lima, 1995).

Destaque especial na atividade de processamento técnico do documento fotográfico merece o Instituto Nacional de Fotografia (INFotoFUNARTE-RJ) que, através do Programa Nacional de Preservação e Pesquisa da Fotografia, teve atuação marcante na disseminação de uma consciência de valorização de acervos fotográficos em arquivos públicos.

Voltado principalmente para a orientação no tratamento técnico e documental, bem como na conservação de suportes fotográficos, o programa preocupou-se em difundir este conhecimento em âmbito nacional, promovendo inúmeros seminários e cursos não só no Rio de Janeiro, como em São Paulo, além de prestar assessoria na organização e preservação de importantes acervos públicos (Museu Mariano Procópio-MG, Museu Antropológico Diretor Pestana ljuí-RS, Instituto Joaquim Nabuco-PE, entre outros) ${ }^{2 i}$.

A atuação do INFoto deve ser compreendida no contexto maior da história da preservação do patrimônio público nacional, cuja orientação sempre teve como baliza, guardadas as especificidades circunstanciais, a constituição de uma "memória nacional". Não seria pertinente, neste trabalho, tratar de tema tão vasto e já bem documentado, mas apenas apontar os parâmetros do desenvolvimento da fotografia documental praticada no Brasil desde a década de 1930 nos orgãos públicos culturais. O poeta Mário de Andrade, nas suas atribuições de Diretor do Departamento do Patrimônio Histórico da cidade de São Paulo e posteriormente de assistente técnico do então SPHAN (Serviço de Proteção ao Patrimônio Histórico e Artístico Nacionall, dedicava especial atenção à documentação fotográfica do patrimônio arquitetônico e artístico do país, chegando a explicitar a maneira de coleta, armazenamento e recuperação da informação (Alvim \& Guimarães, 1981:15). 
Igual preocupação já vinha mobilizando a Comissão Estadual responsável pela organização do I Encontro de Fotografia e Memória Nacional (1981), que, sob a coordenação do pesquisador Boris Kossoy, promoveu trabalhos de documentação fotográfica nas regiões do interior de São Paulo, onde ainda era possivel encontrar remanescentes de antigas fazendas de café (Bellia, 1980), na cidade de São Paulo (D’Ávila, 1980), na ferrovia MadeiraMamoré (Santilli, 1987), entre outros. Além da publicação da série "registros", no MIS (Museu da Imagem e do Som de São Paulol foram organizadas exposições dos ensaios realizados (Kossoy, 1981:10).

Essa preocupação com a preservação de acervos fotográficos e com seu uso numa perspectiva histórica, que caracteriza a década de 1980, pode ser observada também pela presença de artigos voltados para temas que relacionam história e fotografia em jornais de ampla circulação e especialmente na revista Iris $^{22}$.

História da Fotografia $(\mathrm{HF})$

Os repertórios documentais, por veicularem, muitas vezes, informações sobre a trajetória de fotógrafos, seus temas favoritos, os estúdios existentes, as técnicas utilizadas, não deixam de tocar os temas próprios da história da fotografia. No entanto, observa-se a existência de um conjunto significativo (97 obras) de publicações que se detiveram especificamente no aparecimento e expansão do suporte fotográfico.

Não é comum, neste campo, produções de caráter "enciclopédico"23, isto é, que apresentem, de forma sistemática e abrangente, tanto em termos espaciais quanto temporais, a trajetória do suporte fotográfico no Brasil. A maioria das publicações (os livros totalizando $34 \%$ do total e os artigos, $33 \%$ ) se divide em uma infinidade de subtemas - biografias, fotojornalismo, lambe-lambe, depoimentos, cartão postal, fotografia moderna, fotografia no teatro, manuais fotográficos, fotografia impressa em periódicos, fotografia estereoscópica, fotonovela, etc. Neste universo bastante diversificado se destacam, ao lado das obras mais abrangentes, aquelas de cunho biográfico.

As obras de maior envergadura cobrem basicamente o século XIX, e caracterizam-se pela ênfase no desenvolvimento tecnológico e na esfera da produção fotográfica, esta última marcada por uma abordagem biográfica, onde são tratadas as atividades dos fotógrafos que atuaram nos principais centros urbanos do país lorigem, temas preferidos, sociedades realizadas, estúdios montados, premiações, técnicas utilizadas, etc). Em São Paulo, o pesquisador Boris Kossoy prima por ter sido um dos primeiros estudiosos da história da fotografia a empreender uma ampla pesquisa de campo que permitiu situar a atividade fotográfica no Brasil, no século XIX, de maneira sistemática. Seus esforços na montagem de um quadro histórico sobre a trajetória da atividade fotográfica nacional datam de meados dos anos 70 e sua extensa produção abrange, atualmente, não só a história da fotografia propriamente divulgada em publicações específicas sobre o tema e em introduções a repertórios documentais - mas também reflexões teóricas e metodológicas em torno da significação social da imagem fotográfica.
21. As iniciativas deste programa datam de 1980 , resultado de seminários promovidos pela FUNARTE e pelo Museu da Imagem e do Som, em São Paulo, nos quais se constatou o alarmante estado de conservação dos acervos fotográficos no Brasil. João Sócrates de Oliveira colaborou inicialmente no programa que teve continuidade com a integração, a partir 1983, do conservador Sérgio Burgi, que percorreu os principais acervos fotográfi$\cos$ do país detectando os problemas existentes (Cf. Züniga, 1993: 155-162).

22. Fundada em 1947, a Revista Íris, especializada em fotografia, visava principalmente o fotógrafo amador. Num primeiro momento a ênfase maior era para as questôes relativas à técnica de fotografar. No decorrer de seus quase 50 anos e vários subtítulos (Revista Brasileira de Foto, Cinema e Artes Gráficas, Revista Brasileira de Foto-cinematografia, Revista Brasileira de Fotografia, Cinematografia e Gravação Magnética, Revista de Fotografia, Vídeo e Som, Revista de Fotografia, Cinema e Som e finalmente, Revista de Imagem a partir de 1987, até hoje), dedicou atenção também a outros temas, como o cinema e a atividade fonográfica. Nos últimos 10 anos, no entanto, a imagem fotográfica consolidou-se como 
tema principal. A partir de meados da década de 1970 e, principalmente, nos anos 80 , os artigos se diversificam abordando as relaçôes da fotografia com a publicidade, filosofia, história, educação, psicologia, etc. - $61 \%$ dos artigos dessa natureza foram escritos entre 1980 e 1989 , sendo que a maior parte entre o triênio de 1980-1982. Conferir, ao final deste texto, listagem de artigos levantados na Revista Íris que se enquadram no recorte proposto por este ensaio.

23. Os trabalhos mais abrangentes foram produzidos por Gilberto Ferrez e Boris Kossoy, e contemplam o século $\mathrm{XIX}$, estendendo se, no caso do primeiro autor, até o início dos anos 20 deste século.

24. Neste conjunto há somente uma tese de doutorado dos anos 1980.

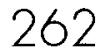

São ainda mais raros e circunscritos a pequenas cronologias os trabalhos que se preocupam em abordar aspectos da circulação fotográfica ou formas de produção já com características de massificação. De difícil confecção, especialmente quando se trata de remontar os circuitos de consumo, e exigindo a articulação da análise fotográfica a outras fontes documentais e a diferentes práticas sociais, este tipo de abordagem aponta para uma possível e fecunda ramificação da história da fotografia, que deverá utilizar o modo de produção visual na compreensão das diferentes formas de relações sociais.

A história da fotografia tende a torna-se aqui uma possivel história social. A coletânea de artigos reunidos por Annateresa Fabris (Edusp, 1991) é representativa das recentes incursões nesse campo, com abordagens que discutem o impacto do consumo fotográfico no campo da arquitetura (Carvalho \& Wolff, 1991:131-172), no fotojornalismo (Costa, 1991:261-292) e a formação profissional do fotógrafo a partir da análise de manuais de fotografia (Mendes, 1991:83-130). Novos recortes começam a ser elaborados, como a presença da fotografia nas exposições universais (Turazzi, 1995), no totojornalismo (Peregrino, 1991; Costa, 1992), na imprensa (Dias, 1993), na publicidade (Goulart, 1988), ou ainda o estudo das práticas sociais nos ateliês folográficos (Grangeiro, 1993), elc.

Quando se trata de constituir quadros históricos da fotografia no século $X X$, observa-se também uma segunda ramificação voltada para as relações da folografia com o campo da história da arte. Neste contexto, são analisados, sobretudo, os atributos visuais da imagem, especialmente aqueles que identificam as rupturas formais no interior do que se costuma denominar linguagem fotográfica ou as relações desta com modelos pictóricos anteriores ou contemporâneos a ela. Essa linha de análise está presente nas obras de Annateresa Fabris a partir do início desta década, de Alice Brill (1988) e tem orientado estudos de caso que abordam temas tão variados como a representação da natureza na pintura e na fotografia (Carvalho, 1991:199-231), a fotomontagem e os pré-rafaelistas (Pavan, 1991:233-259), ou ainda as relações entre a fotografia e a pintura acadêmica paulista (Carvalho \& Lima, 1993:147-174).

Provavelmente por exigir maior tempo de pesquisa na sua confecção, as obras sobre a história da fotografia surgem, na sua maioria, através de financiamentos de instituições públicas $(58 \%)$. As editoras privadas publicaram somente $17 \%$ das 97 obras que formam esta categoria.

Com exceção do artigo pioneiro de Gilberto Ferrez sobre a atuação do fotógrafo Marc Ferrez, publicado em 1946, os trabalhos sobre o tema história da fotografia datam dos anos de 1970 (16) e quase duplicam na década de 80 (34), acompanhando a curva ascendente de publicaçōes documentais. Nos anos 90, mantém-se o nível de produção, porém com uma característica peculiar: metade dos trabalhos realizados nesta década teve origem nas universidades como dissertações de mestrado ${ }^{24}$. O fato dos trabalhos acadêmicos se referirem à titulação de mestre indica como o tema alcança tardiamente o meio universitário e começa a formar um grupo de pesquisadores especializados.

Isso nos faz pensar que a fotografia como tema de pesquisa se impôs primeiro nas instiłuições públicas, porém vinculada às iniciativas de 
organização de arquivos, "descoberta" de coleções e montagens de exposições. Exemplo deste processo é a atuação do CPDOC /Centro de Pesquisa e Documentação da História Contemporânea do Brasil da Fundação Getúlio Vargas-Rj ${ }^{25}$ ) que, paralelamente às atividades de organização documental de coleções fotográficas, desenvolveu um amplo programa de pesquisas, cujo objetivo era justamente valorizar a fotografia enquanto fonte histórica. No campo de interesse do CPDOC, a história política, seus pesquisadores dedicaram-se a analisar as relações entre fotografia e propaganda partidária a partir de conjuntos fotográficos referentes às Revoluções de 30 e 32 e à trajetória de Getúlio Vargas, tendo produzido inúmeros artigos, mostras e exposições ao longo dos anos 80 . Contudo, é somente nos anos 90 que a fotografia passa a ganhar terreno como fonte documental para a pesquisa acadêmica.

Novamente o eixo São Paulo-Rio de Janeiro se afirma como maior centro de edição, com a cidade de São Paulo publicando $45 \%$ das obras e o Rio de Janeiro, 35\%. Este conjunto é o único no qual autores brasileiros publicaram, com alguma expressividade, em outros países (três edições em Paris, em 1986; uma em Houston, em 1988; uma em Albuquerque/Novo México, em 1990; duas em Nova Yorque, em 1976 e em 1980; e uma no México, em 19781. A cronologia de interesse continua sendo o século XIX, estendendo-se até os anos 20 , porém é significativo o número de obras que se dedicam ao século $X X$.

\section{Teoria e Metodologia (TM)}

No conjunto de obras que tratam de teorias e metodologias associadas à compreensão histórica do fenômeno fotográfico a ausência de grandes investimentos intelectuais se faz notar com maior evidência. Em um universo reduzido a 40 publicações, os artigos representam $77 \%$, os livros apenas $12,5 \%$ e o número de teses é insignificante $110 \%)$. Produzidos no interior de instituições públicas, principalmente na esfera universitária, estes trabalhos tornamse mais freqüentes a partir dos anos 80 , sendo que os anos 90 contam com o mesmo número de publicações da década anterior, demonstrando um crescimento de obras deste tipo. O eixo São Paulo - Rio de Janeiro continua concentrando a produção, porém adquirindo algum destaque a cidade de Campinas/SP.

Mais de um terço das obras desse conjunto é de autoria de estudiosos que já desenvolveram pesquisas tendo como fonte histórica a fotografia (Kossoy, Leite, Lissovsky, Lobo). Nestes casos os temas dos artigos giram, predominantemente, em torno das relações entre fotografia e história. Caracterizam-se, portanto, por uma preocupação em postular as especificidades das fontes iconográficas, consideradas ainda pouco exploradas e a necessidade de encaminhamentos metodológicos adequados, procedendo a pequenos balanços de obras estrangeiras que trataram este tema ou questões relacionadas à gênese da fotografia (tais como Bourdieu, Barthes e Sontag, para citar apenas os mais recorrentes).

Balanços da produção nacional de historiadores que se voltaram para o estudo da visualidade articulada a práticas sociais são quase
25. Criado em 1973, o CPDOC reúne arquivos privados de homens públicos, a partir dos quais desenvolve atividades de documentação e pesquisa. Em 1979, é criado o Subsetor Audiovisual especialmente dedicado à documentação fotogrâfica (Lobo, Brandâo \& Lissovsky, 1987: 39-52). 
inexistentes, com exceção do artigo do historiador Marcos Silva (1992:117134) que analisa teses recentes que abordam produtos visuais na perspectiva histórica: Sua reflexão sobre essa produção no meio acadêmico reforça a necessidade de discussões metodológicas mais amplas além de atestar falhas na formação de graduandos no que se refere às atividades de pesquisa e contato com fontes visuais (p. 118).

0 "realismo" da fotografia e, por decorrência, o estatuto de veracidade atribuído aos documentos fotográficos são pontos chaves abordados neste conjunto, não só por aqueles que trabalham com a fotografia numa perspectiva histórica, mas também entre os autores oriundos da área de comunicação e semiótica (Entler, 1994; Rocha, 1991; Oliveira Jr, 1994).

\section{A Fotografia como Significação Histórica (SH)}

Muitas das obras que se propõem a analisar a produção de sentidos no uso da fotografia pela sociedade acabam por explicitar, seja indiretamente, seja em um capítulo à parte, problemas relativos à teoria e, especialmente, à metodologia no processamento da informação visual. Voltados para o tratamento de séries documentais, estes trabalhos quase sempre se vêem obrigados a explicitar os caminhos adotados para a análise.

Por outro lado, estas obras possuem um aspecto aplicativo que o conjunto anterior não possui. É preciso considerar ainda que este tipo de produção não deixa de ser também um modo de constituição da própria história da fotografia.

É provável que o número proporcionalmente reduzido de obras neste conjunto $(60)$ se deva ao seu desenvolvimento recente: $75 \%$ da produção são dos anos 90. Mais interessadas na compreensão dos processos sociais do que propriamente na trajetória específica da fotografia, estas obras têm um perfil quase exclusivamente acadêmico. A maioria esmagadora foi produzida na esfera pública, e nesta, 53\% têm origem universitária, destacando-se São Paulo, Campinas, e, em seguida, o Rio de Janeiro. Entre as sete obras editadas, três foram originalmente teses.

A falta de tradição neste campo se faz perceber pelo número predominante de artigos $(63 \%)$ e de teses $(20 \%)$, a maioria de mestrado. A cronologia escolhida oscila entre o século XIX e a virada do século $(50 \%)$, porém o número de trabalhos que se dedicam a períodos mais recentes não deixa de ser significativo (40\%).

Os temas mais recorrentes (43\%) são aqueles associados às representações da cidade e da família, o que é esperado, já que a produção fotográfica é maior nesses campos. A outra metade dos trabalhos se divide, com pequenas variações, entre temas que relacionam a fotografia à arquitetura, ao pictorialismo, às artes plásticas, à fotonovela, ao fotojornalismo, ao museu, às exposições universais, às representações do negro, da saúde pública e da natureza.

Nesses trabalhos, é possível identificar pontos em comum nas metodologias de análise aplicadas. $\bigcirc$ primeiro deles é o tratamento seriado. Presente em análises de conjuntos documentais maciços, este tratamento 
caracteriza-se, grosso modo, pelo estabelecimento de núcleos que guardam semelhanças formais e/ou temáticas, e cujo encaminhamento das hipóteses de trabalho derivam justamente da reflexão sobre as associações de sentido inferidas no confronto entre os atributos observados ao longo das séries. Principalmente nos estudos desenvolvidos no campo das representações sociais e em virtude da disseminação da fotografia enquanto produto de massa, abordagens desta natureza são mais recorrentes. O arcabouço metodológico envolve a constituição de categorias que permitem operar a massa documental e identificar o comportamento de variáveis (Leite, 1991, 1993; Essus, 1990, 1994; Carvalho, 1995; Lima, 1995).

Mesmo para conjuntos documentais pequenos (menos de 50 fotografias) são adotados procedimentos quantitativos que controlam os atributos formais e temáticos. Essa tendência metodológica pode ser observada no número especialmente dedicado à fotografia da revista Acervo (RJ, v.6 n. 1-2, 1993), onde cinco dos treze artigos se caracterizam por estudos de casos onde é aplicado o tratamento seriado com vistas à identificação de tipologias, padrões, etc.

No caso do Boletim do Centro de Memória da UNICAMP, a idéia de se publicar um número especial sobre fotografia surgiu da necessidade sentida pelos pesquisadores do centro da "utilização adequada de fotografias nas pesquisas em ciências sociais" (Simson, 1993:9)26. Foram convidados pesquisadores de diferentes áreas (antropologia, história, artes, arquivística), objetivando justamente apresentar a diversidade de aplicações da fotografia na produção de conhecimento sobre a sociedade e os problemas recorrentes enfrentados no trato com a documentação fotográfica.

O segundo ponto de aproximação diz respeito às premissas teóricas. Os trabalhos que se preocupam em explicitar a metodologia adotada buscam compreender a "mensagem fotográfica" ou os elementos constitutivos de sua significação através de uma relação "triádica", ou seja, intermediada pelo "interpretante" da imagem. Este modelo revigora a idéia de construção da imagem fotográfica e portanto de produção de sentido e questiona o estatuto de veracidade ou reprodução fiel da realidade, que teria seu modelo estruturado a partir de uma relação dual, sem mediação.

Nos trabalhos acadêmicos produzidos no campo da semiótica, o realismo fotográfico é referenciado a partir das discussões em torno do caráter indicial da fotografia, e que mobilizou teóricos como Philipe Dubois, Schaeffer e Umberto Eco. A especificidade da fotografia estaria na sua qualidade de índice (por ser resultado de uma "marca" da luz num suporte sensívell, muito embora ela pudesse também ser incluída na categoria de ícone ou até mesmo de símbolo (pensando-se na existência de um código fotográfico). Oliveira Jr. (1994), ao historicizar as polêmicas acerca da definição sígnica da fotografia, discute o "encantamento" com esse aspecto indicial questionando essa abordagem: "E se a fotografia é considerada semelhante ao seu referente, é porque ela obedece a um sistema de representação técnica vigente na nossa sociedade, e não porque seu referente "adere" à superfície sensivel." |Oliveira $\mathrm{Jr}$, 1994:59|. Para o autor, as análises da linguagem fotográfica empreendidas por Arlindo Machado constituiriam o ponto de partida para desacreditar essa
26. O Centro de Memória da Unicamp, criado em 1985, pubilca, a partir de 1989 , o Boletim do Centro de Memória, que procura sistematizar e divulgar semestralmente os trabalhos produzidos pelo centro, além de seus acervos. No final de cada volume existe uma relação de pesquisadores que procuraram o centro, com o tema de sua pesquisa, finalidade e endereço para contato. Até o volume 5 , os boletins se caracterizavam pela variedade de assuntos, o primeiro volume com um eixo temático, foi 0 volume 5 , n.10, cujo tema é a fotografia. 
27. Trabalhos de antropologia visual parecem esbarrar neste mesmo problema. Aqui a fotografia preenche quase uma função auxiliar no trabalho sociológico. As fotografias "quentes" sâo aquelas que podem ser associadas a depoimentos orais que descrevem a situação fotografada, as condições e intençôes do registro. Para Simson, que reuniu um conjunto de 500 fotografias de carnaval datadas descie o século passado até as décadas recentes, "uma fotografia sozinha não permite fazer muitas inferências de caráter histórico-sociológico, ela deve necessariamente ser associada a outros dados de pesquisa (depoimentos orais, documentos, mapas, dados bibliográficos, além de outras fotos) para que as informações que contém possam ser visualizadas pelo pesquisador dentro de um contexto mais amplo, que permitirá a ele explorar ao máximo os dados registrados naquele suporte fotográfico." (Simson, 1991:21) 28. PANOFSKY, Erwin. Significado nas Artes Visuais. São Paulo. Perspectiva, 1979. crença de "impressão da realidade"(p. 52). Entre aqueles pesquisadores que se utilizam de conceitos desenvolvidos no campo da semiótica, Essus (1990) merece destaque na medida em que propõe uma análise "histórico-semiótica" das imagens fotográficas, postulando uma necessária articulação entre a análise semiótica e a dimensão histórica e social das práticas produtoras de sentido.

O terceiro ponto de convergência recai em uma aparente contradição. Embora encontremos sempre explicitada a crença na especificidade da linguagem visual e no seu potencial histórico, a ênfase nas limitações do documento visual sugere a existência, ainda, de um estranhamento deste objeto de análise (Leite, 1988; Kossoy, 1989; Lacerda, 19931. As limitações apontadas - falta de identificação da técnica, da aparelhagem utilizada, da autoria ou mesmo dos personagens ou motivos da imagem - não são, certamente, restrições exclusivas do documento fotográfico; todo e qualquer documento, se não for devidamente identificado e contextualizado pode inviabilizar o encaminhamento de hipóteses de trabalho. Este desconforto atribuído à fotografia revela o caráter ainda pouco sólido dos estudos em uma área sem tradição de pesquisa. Nesse sentido, é curioso observar em alguns trabalhos que, muito embora se apresentem pressupostos teóricos para uma análise da imagem fotogrática que leva em consideração sua especificidade enquanto produtora de sentido, na prática se opta por um histórico do objeto de estudo (a cidade, o negro, a imigração, etc) explorando-se muito pouco a multiplicidade de mensagens possível de ser extraída dos conjuntos fotográficos selecionados (Cf. Olszewski, 1989; Barboza, 1992; Rauh, 1992; Ribeiro, 19941.

Por fim, a utilização de termos tais como memória, passado, reconstituição e reconstrução, presentes, como já visto, nos repertórios documentais, também caracteriza as reflexões que se propõem a entender a fotografia como produção de sentido. Em Miriam Moreira Leite (1988, 1991, 1993). pesquisadora voltada para a história da família no Brasil a partir de representações sociais veiculadas pela fotografia, a referência à memória é abstrata, ou seja, a fotografia é capaz de "despertar" a lembrança, de trazer à superfície o registro mental coletivo ${ }^{27}$.

A vivência passada, perdida entre tantos registros mentais, poderia ser desencadeada pela fotografia, consumando um processo de recuperação do passado. A tarefa de reconstituição aparece como inerente ao trabalho de pesquisa com fotografia de família na medida em que: "Como é imóvel e estática (a fotografia) representa um tempo presente, um agora diante do que o pesquisador é levado a reconstituir o que levou aquelas personagens a estar ali, assim, daquele jeito, naquele momento, para poder prever o desenlace, os momentos seguintes que podem vir a ser encontrados em outros instantes isolados, em outras fotografias." (Leite, 1986: 1489). Essa linha de abordagem aproxima-se dos métodos desenvolvidos no campo da antropologia visual e enfatiza a utilização combinada de fontes orais e fotográficas, na busca de uma "reconstituição histórica" do passado familiar ou de membros de uma comunidade (Simson, 1989; Campos, 1992; Ribeiro, 1994).

Ao discutir a interpretação iconológica das fotografias tendo como orientação a metodologia para análise de imagens desenvolvida por Panofsky ${ }^{28}$, 
Kossoy alerta para os perigos de se buscar uma "reconstituição da realidade passada" na medida em que: "A fotografia ou um conjunto de fotografias não reconstituem os fatos passados. A fotografia ou um conjunto de fotografias apenas congelam, nos limites do plano da imagem, fragmentos desconectados de um instante de vida das pessoas, coisas, natureza, paisagens urbana e rural. Cabe ao intérprete compreender a imagem fotográfica enquanto informação descontínua da vida passada, na qual se pretende mergulhar" (1989:78).

Essa descontinuidade provocada pelo que se vulgarizou como o "congelamento" do instante, ou a natureza indicial da fotografia, ou ainda a "ficção temporal" (Oliveira Jr 1994:41), pode levar a uma negação da história, se a entendermos como processo de mudança. Mais do que isso, ela pode dificultar o entendimento da fotografia como representação, e, como tal, também parte da realidade sensível.

No entanto, essa é precisamente uma das qualidades da fotografia que permitiria extrair dela informações específicas para a produção de conhecimento histórico, não substituível por nenhum outro tipo de documento. Longe de preocupações com a reconstituição do passado, deve-se procurar uma metodologia de análise capaz de interpretar o referente fotográfico, que como tal está inserido no conjunto das relações sociais, e, portanto, só adquire pleno sentido como um dos agentes deste universo.

\section{Conclusão}

Em linhas gerais, o que se percebe ao longo dos últimos 17 anos $^{29}$ no campo da produção bibliográfica sobre o tema "fotografia e história" é uma forte presença institucional, reforçada recentemente pela produção acadêmica, movimento este relacionado com a passagem de uma fase predominantemente empírica e descritiva para um novo momento de reflexão e análise.

A produção é irregular no que se refere à qualidade e ao rigor conceitual das análises teóricas, para o que concorre o desconhecimento de pesquisas afins estrangeiras. Se pensarmos em termos númericos, a defasagem em relação à produção estrangeira, especialmente a americana, aumenta ainda mais ${ }^{30}$.

O saldo, no entanto, é extremamente positivo. Sem dúvida nenhuma, as fontes fotográficas mobilizam hoje um número expressivo de cuidados que inspiram a sua exploração histórica. Nos principais museus, arquivos e bibliotecas do país o documento fotográfico não é mais relegado à categoria de segunda classe, complemento ilustrativo tratado como um apêndice da documentação textual. A preocupação em dispensar um tratamento técnico de catalogação e de acondicionamento físico específicos demonstra claramente a mudança de status da fotografia nesse campo.
29. Os anos 80 marcam uma verdadeira explosão do interesse pela fotografia. Porém na Universidade de São Paulo podem ter sido produzidos trabalhos de graduação sobre o tema já nos anos 30, como o de Benedito Duarte, então aluno de direito, e que escreveu sobre a fotografia criminalística. Benedito Duarte é também apontado como um dos "primeiros historiadores informais" da fotografia, ao lado de Eduardo Salvatore, em virtude dos textos publicados em jornais $e$ revistas. (Cf. Camargo \& Mendes, 1992: 117,130). 30. Simson (1991:14-24), ao realizar um pequeno balanço da produção acadêmica que utiliza fontes fotográficas, observa que "Os Estados Unidos talvez sejam hoje o país que mais utiliza a fotografia como técnica auxiliar da pesquisa sociológica. Existe mesmo funcionando naquele país uma Associação Internacional de Semiólogos Visuais com reuniões regulares $\mathrm{e}$ publicaçōes." (p.17). De fato, a produçâo americana é vastíssima. A revista Visual Re sources, dedicada a divulgar trabalhos que explorem fontes visuais publicou, em 1994 ( $v$ X, n.2, p. 165-206), uma bibliografia em que são arrolados mais de 500 títulos de obras (entre artigos, livros e catálogos) editados somente no ano de 1991. Deste total, 70 referem-se especificamente à fotografia (história, questões metodológicas e apresentaçào de coleções). 
A agilidade no armazenamento e no acesso aos acervos possibilitada pela informática, e que tende a ocupar lugar de destaque nos trabalhos em reservas técnicas e na interação com o grande público, coloca à disposição uma grande massa documental, abrindo novas perspectivas para a pesquisa.

A ascendente produção de obras observada neste ensaio certamente terá continuidade, principalmente se pensarmos na democratização da informação científica proporcionada pela rede Internet que já é realidade para muitas instituições de ensino e pesquisa no país.

Agradecimentos

Gostaríamos de agradecer a todos aqueles que colaboraram com o levantamento bibliográfico, especialmente aos que se dispuseram a discutir e enriquecer este trabalho como o Prof. Dr. Ulpiano Toledo Bezerra de Meneses do Depto de História da FFLCH-USP e Ricardo Mendes da Divisão de Pesquisas do Centro Cultural São Paulo.

\section{ANEXO: NOTA BIBLIOGRÁFICA}

ALVIM, Zuleika; PEIRÃO, Solange. Mappin setenta anos. São Paulo: Ex-Libris, 1985; BOAVENTURA, Maria Eugênia. O salão e a selva. Campinas: Editora da UNICAMP/Ex-Libris, 1995, 286p.; COMPANHIA PAULISTA DE FORÇA E LUZ. Memória bistórica da CPFL: 19121992. São Paulo: CPFL, 1992, 57p.; DONATO, Hernâni. Cem anos da Melhoramentos: 18901990. São Paulo: Melhoramentos, 1990, 176p.; GONÇALVES, Vergniaud Calazans. A primeira corrida na América do Sul. São Paulo: Empresa das Artes, 1988, 91p.; HANDA, Tomoo. O imigrante japonês: história de sua vida no Brasil. São Paulo: T.A.Queiroz, Centro De Estudos Nipo-Brasileiros, 1987, 828p.; HOMEM, Maria Cecília Naclério. O prédio Martinelli: a ascensão do imigrante e a verticalização de São Paulo. São Paulo: Projeto, 1984, 175p. (originalmente dissertação de mestrado); LAMONIER JR, Gastão. Leme de ontem e de boje, 1900-1983. Rio de Janeiro: s.e., 1983, 39p.; LEMOS, Carlos A. C. Ramos de Azevedo e seu escritório. São Paulo: Pini, 1993, 165p.; LIGHT. Cinquenta anos de progresso com São Paulo: 1900-1950. São Paulo: Light, s.d.; MASCARO, Cristiano. A fotografia e a arquitetura. São Paulo, 1994. Faculdade de Arquitetura e Urbanismo - Universidade de São Paulo. Tese (Doutorado); MOTA, Carlos Guilherme; LOPEZ, Adriana. Brasil revisitado: palavras e imagens. São Paulo: Rios, 1989; NOSSO século, memória fotográfica do Brasil no século XX. São Paulo: Abril Cultural, 1980, 6vs; O VALE do Paraỉba ontem e boje. S.1.: AC\&M Editora/Monsanto, 1989. Fonte: Boca Livre/O Vale do Paraíba. Irisfoto. n.422, p.20, jan.-fev. 1989; PESAVENTO, Sandra Jatahy (Org.). O espetáculo da ma. Porto Alegre: Ed. Universidade/UFRGS, Prefeitura Municipal, 1992, 95p.; PROJETO Pró-memória Farroupilha. Rio Grande do Sul: Banco Bamerindus do Brasil/RBSRede Brasil Sul de Comunicações, 1985. Fonte: STRELIAEV, Leonid Liane Neves. Irisfoto. n.385, p.19-21, set. 1985; 15 ANOS: um partido com bistória. São Paulo: Secretaria de Formação Política/PT, 1995; REIS, Ciro Dias. Salão do automóvel: trinta anos de história. São Paulo: Anfavea/MD Comunicação e Editora, 1990, 132p.; SECRETARIA MUNICIPAL DE CULTURA(RJ). Memória de Ipanema:100 anos do bairro. Rio de Janeiro: SMC, 1994, 60p.; SESSO Jr., Geraldo. Retalhos da velha São Paulo. São Paulo: OESP, 1987, 348p.; SOUZA, Edgard de. História da Light: primeiros cinquenta anos. São Paulo, Eletropaulo, 1982, 221p. 


\section{BIBLIOGRAFIA}

Cada referência bibliográfica possui, ao final, o código de uma ou mais das cinco categorias abaixo relacionadas. A indicação com maiúsculas refere-se àquela que serviu de parâmetro para a análise:

História da Fotografia $-\mathrm{HF}$
Processamento Técnico - PT
Repertório Documental - RD
Significação Histórica

ÁlBUM comparativo da cidade de São Paulo. Organizado pelo Exmo. Sr. Dr. Washington Luiz Pereira de Souza. Prefeitura Municipal de São Paulo: s.e., 1916. 2v. (119 fotografias originais). (RD)

ÁlBUM comparativo da cidade de São Paulo até o anno de 1916. Organizado por Washington Luiz Pereira de Souza. São Paulo: s.e., s.d. 2v. (112 fotografias originais). (RD)

ÁlBUM comparativo da cidade de São Paulo. Organizado com autorização do Exmo. Sr.Dr. Washington Luiz Pereira de Souza. São Paulo: s.e., s.d. 2v. (aprox.1916) (113 fotografias originais). (RD)

ÁLBUM comparativo da cidade de São Paulo: 1862-1887-1914. São Paulo: Casa Duprat, 1914. $2 \mathrm{v}$. (103 fotografias originais). (RD)

ÁLBUM-lembrança da exposição iconográfica e bibliográfica bahiana realizada entre 05.11 .49 e 05.01.50 nos salões do Paço do Saldanha. Salvador: Prefeitura Municipal de Salvador, 1951. $168 \mathrm{p} .(\mathrm{RD})$

ALVARENGA, Alexandre Curtiss. O mundo todo nos detalbes do cotidiano: aspectos teóricos da gênese e da significação na fotografia documentária. Campinas, 1994. Dissertação (Mestrado) - Instituto de Artes, Universidade Estadual de Campinas. (HF, tm)

ALVES, Ênio Leite. O fotojornalismo nos momentos de crise: a morte de Getúlio e Tancredo. São Paulo, 1990. Dissertação (Mestrado) - Escola de Comunicações e Artes, Universidade de São Paulo. (SH, hf)

ALVES, Paulo; MASSEI, Roberto Carlos. Fotografia e História. História, São Paulo, n.8, p. 81-86, 1989. (TM)

ALVIM, Clara de Andrade. Fotografia e Memória. In: MUSEU DA IMAGEM E DO SOM. I Encontro de Fotografia e Memória Nacional. São Paulo: Secretaria da Cultura, 1981. p.1323. (RD)

AMARAL, Aracy A. Aspectos da comunicação visual numa coleção de retratos. In: MOURA, Carlos Eugênio Marcondes de, Org. Retratos quase inocentes. São Paulo: Nobel, 1983. p.115-179. (SH) 
AMORIM, Paulo et al. Partidos e politicos. Rio de Janeiro: Jornal do Brasil, 1982. (RD) Fonte: LIMA, Ivan. Os políticos nas fotografias e na história (documento). Íris. n.356, jan.fev. 1983, p.14-15.

ANDRADE, Jairo de Araújo. Fotografia: aspecto da evolução em Sergipe. Sergipe: Ótica Santana, 1989. 52p. (RD)

ANDRADE, Joaquim Marçal Ferreira de. Novas fontes para o estudo do século XIX: o acervo fotográfico da Biblioteca Nacional e o projeto de conservação e preservação PROFOTO. Acervo Revista do Arquivo Nacional, Rio de Janeiro, v.6, n.1-2, p. 133-144, jan.-dez. 1993. (RD)

ANDRADE, Mário de. Mário de Andrade: fotógrafo e turista aprendiz. São Paulo: Instituto de Estudos Brasileiros, 1993. (RD)

ANDRADE, Milton. O pioneirismo de Gioconda. Memória. São Paulo, n.12, p. 10, jul.-ago.-set. 1991. (HF)

ARQUIVO GERAL DA CIDADE DO RIO DE JANEIRO. Augusto Malta: catálogo da série negativo em vidro. Rio de Janeiro: Secretaria Municipal de Cultura/ Departamento Geral de Documentação, 1994. 1v. 124p. (Biblioteca carioca, v.29. Série instrumentos de pesquisa). (PT, rd)

ARQUIVO PÚBLICO ESTADUAL (ES). Catálogo de documentos especiais: acervos fotográficos, 1951-1955. Vitória: Arquivo Público Estadual de Vitória, 1991. 126p. (Memória Capixaba. Documentos especiais, n.2). (RD)

ASSOCIAÇÃO DE CARTOFILIA (RJ). Cartão postal: fascínio e memória/ Solar Grandjean de Montigny. Rio de Janeiro: O Solar-PUC/RJ, 1986. 64p. (Catálogo de exposição). (RD, hf)

AZEVEDO, Militão Augusto de. Álbum comparativo da cidade de São Paulo: 1862-1887. São Paulo: s.e., 1887. (60 fotografias originais) (RD)

AZEVEDO, Paulo Cesar de; LISSOVSKY, Maurício. O fotógrafo Christiano Jr. In: AZEVEDO, Paulo Cesar de; LISSOVSKY, Maurício, orgs. Escravos Brasileiros do século XIX na fotografia de Christiano Jr. São Paulo: Ex-Libris, 1988, p.9-15. (HF, rd)

BAHIA de ontem e de hoje. Salvador: Prefeitura Municipal, 1953. (RD)

BARBOZA, Naide. Em busca de imagens perdidas: centro histórico de Aracaju, 1900-1940. Aracaju: Fundação Cultural da Cidade de Aracaju, 1992, 88p. (SH)

BARDI, Pietro Maria. Em torno da fotografia no Brasil. Rio de Janeiro: Banco Sudameris Brasil, 1987. (HF)

BARROS, Geraldo de. Fotoformas: Fotografias. São Paulo: Raízes Artes Gráficas, 1994. (Catálogo de exposição) (RD) 
BARROS, Lenora de. O tempo na fotografia. Arte em São Paulo, São Paulo, n.15, não pag., 1983. (TM)

BARROS, Myriam Moraes Lins de; STROZENBERG, Ilana. Álbum de família. Rio de Janeiro: Comunicação Contemporânea, 1992. (RD)

BELMIRO, Célia Abicalil. A fotografia na construção visual da gravidez. Rio de Janeiro, 1992. 153p. Dissertação (Mestrado) - Centro de Filosofia e Ciências Humanas, Universidade Federal do Rio de Janeiro. $(\mathrm{SH}, \mathrm{tm})$

BERARDO, Rosa Maria Xingu. O olhar fotográfico. São Paulo, 1990. Dissertação (Mestrado) Escola de Comunicações e Artes, Universidade de São Paulo. (SH, tm)

BERGER, Paulo. O Rio de ontem no cartão-postal: 1900-1930. Rio de Janeiro: RioArte, 1983. (RD)

BIBLIOTECA NACIONAL (Brasil). Coleção D. Thereza Cbristina Maria. Rio de Janeiro: Biblioteca Nacional, 1987. 37p. (Catálogo de exposição). (RD)

BIBLIOTECA OLIVEIRA LIMA. Fotografias brasileiras raras da Biblioteca Oliveira Lima. São Paulo: Fundação Padre Anchieta, 1981. 93p. (Catálogo de exposição). (RD)

BOMENY, Regina Helena; MURAKAMI, Ana Maria Brandão. Centro de Pesquisa e Documentação de História Contemporânea do Brasil - Entrevista. Arquivo \& Administração, Rio de Janeiro, v.6, n.3, p. 19-22, set.-dez. 1978. (PT)

BOTELHO JR., Francisco Cassiano. A imagem fotogrăfica e o "real". São Paulo, 1981. Dissertação (Mestrado) - Escola de Comunicações e Artes, Universidade de São Paulo. (TM)

BRANDÃO, Ana Maria de Lima. O acervo fotográfico do CPDOC/FGV. Rio de Janeiro: CPDOC,1980. (PT)

BRANDÃO, Ana Maria de Lima; LEME, Paulo de Tarso R. Dias Paes. Documentação especial em arquivos públicos. Acervo - Revista do Arquivo Nacional, Rio de Janeiro, v.1, n.1, p. 51-59, jan.jun. 1986. (PT)

BRASÍLIA ANO 20: depoimento de 35 fotógrafos de Brasília. Brasília: Agil/União dos Fotógrafos, 1980. (RD)

BRILL, Alice. A função da fotografia na arte contemporânea. In: BRILL, Alice. Da arte da linguagem. São Paulo: Perspectiva, 1988, p.93-110. (HF)

BRITO, Marilza. Metodologia para o tratamento de acervos arquivisticos. Memória da Eletricidade, Rio de Janeiro, v.13, p. 5-6, mai 1990. (PT) Fonte: Bibliografia Temática. Boletim do Centro de Memória da Unicamp, Campinas, v.5, n.10 jul.-dez. 1993, p.131-142. 
BULHÔES, Antônio; REBELO, Marques. Rio 1900: fotografias de Augusto Malta. Rio de Janeiro: Nova Fronteira, 1976. (RD) Fonte: TURAZZI, Maria Inez. Poses e Trejeitos. Rio de Janeiro: Rocco/Funarte, 1995. 309p.

BURGI, Sérgio. A preservação dos materiais fotográficos: o processamento para permanência. Revista Fotóptica. São Paulo, n.120, p. 2/42/45, s.d. (PT)

BURGI, Sérgio. Introdução à preservação e conservaçâo de acervos fotográficos: técnicas, métodos e materiais. Rio de Janeiro: INFoto/Funarte, 1985. 21p. (2.ed. em 1988) (PT)

CADERNOS do Centro de Memória Regional. Bragança Paulista: Universidade São Francisco, 1993. 65p. (Edição especial: memória fotográfica de Bragança Paulista, 2) (RD)

CAMARGO, Mônica Junqueira de; BARROS, Dayse Ribeiro de Moraes; MUSA, João Luis. A experiência da Divisão de Iconografia do Departamento do Patrimônio Histórico Municipal. In: MUSEU DA IMAGEM E DO SOM. I Encontro de Fotografia e Memória Nacional. São Paulo: Secretaria da Cultura, 1981, p.109-121. (PT)

CAMARGO, Mônica Junqueira de; MENDES, Ricardo. Fotografia: cultura e fotografia paulistana no século XX. São Paulo: Secretaria Municipal de Cultura, 1992. 176p. (HF, rd)

CAMPIGLIA, G. Oscar Oswaldo. Importância de formas fotográficas na atividade de informação bibliográfica e documentária. São Paulo: APB, 1958. (PT)

CAMPOS, Fernando F. Um fotógrafo, uma cidade: Augusto Malta. Rio de Janeiro: Maison Graphique, 1987. (HF, rd)

CAMPOS, Maria Cristina de Souza. A associação da fotografia aos relatos orais na reconstituição histórico-sociológica da memória familiar. Cadernos CERU (Centros de Estudos Rurais e Urbanos), s.1., n.3, 2a. série, 1992. (SH)

CANUDOS - memórias fotográficas. s.l.: s.e., 1990. (RD). Fonte: FERNANDES Jr., Rubens. Boca livre/Canudos, por Antônio Olavo. IRISFOTO n. 435, maio/jun.1990.

CARDOSO JR, Fernando Antônio. A história e a crítica de fotografia. Belo Horizonte: Universidade Federal de Minas Gerais, 1991. (HF) Fonte: Banco Bibliográfico sobre fotografia/ Div. de Pesquisa do Centro Cultural São Paulo.

CARDOSO, Elizabeth Dezougart et al. História dos bairros Saúde - Gamboa - Santo Cristo. Rio de Janeiro: João Fortes Engenharia/Index, 1987. (RD)

CARDOSO, Sílvia H. S. Onde está a fotografia? Cadernos Estética, São Paulo, n. experimental, p.30-31, dez. 1989. (TM)

CARNEIRO, Maria Luiza Tucci. Revolução de 30: um estudo através da imagem. Perspectivas do ensino de bistória. Anais, São Paulo, 1988. (SH) 
CARNICEL, Amarildo Batista. O fotógrafo Mário de Andrade. Campinas: Editora da UNICAMP, 1994, 151p. Originalmente Dissertação (Mestrado). (SH)

CARVALHO, Aurea Maria de Freitas. Fotografia como fonte de pesquisa: histórico, registro, arranjo, classificação e descrição. Rio de Janeiro: Fundacao Nacional Pró-Memória/Museu Imperial, 1986. 52p. (PT)

CARVALHO, Maria Cristina Wolff de; WOLFF, Silvia Ferreira Santos. Arquitetura e fotografia no século XIX. In: FABRIS, Annateresa, Org. Fotografia: usos e funções no século XIX. São Paulo: Edusp, 1991, p.131-172. (HF)

CARVALHO, Paulo Gutemberg de. A fotografia como fonte de pesquisa. Carta CEPRO, Teresina, v.13, n.1, p.149-160, jan.jun. 1988. (TM)

CARVALHO, Vânia Carneiro de. Do indivíduo ao tipo: as imagens da (des)igualdade nos álbuns fotográficos da cidade de São Paulo na década de 1950. São Paulo, 1995. 358p. Dissertação (Mestrado) - Departamento de História, Faculdade de Filosofia, Letras e Ciências Humanas, Universidade de São Paulo. (SH)

A plasticidade urbana: as representações da cidade de São Paulo nas fotografias de 1950. Acervo - Revista do Arquivo Nacional, Rio de Janeiro, v.6, n.1-2, p.111-120, jan.-dez. 1993. (SH)

A representação da natureza na pintura e na fotografia brasileiras do século XIX. In: FABRIS, Annateresa, Org. Fotografia: usos e funções no século XIX. São Paulo: Edusp, 1991, p. 199-231. (SH)

CARVALHO, Vânia Carneiro de; LIMA, Solange Ferraz de. A cidade musealizada: funções e estratégias visuais nas encomendas pictóricas do Museu Paulista em 1922. Anais do V Congresso Brasileiro de História da Arte, São Paulo, Comitê Brasileiro de História da Arte-ECA/USP, 1995, p.169-174. (SH)

São Paulo antigo, uma encomenda da modernidade: as fotografias de Militão nas pinturas do Museu Paulista. Anais do Museu Paulista Nova Série, São Paulo, n.1, p.147-174, 1993. (SH)

CEZAR, Paulo Bastos; CASTRO, Ana Rosa Viveiros de, orgs. A Praça Mauá na Memória do Rio de Janeiro. São Paulo: João Fortes Engenharia/Ex-Libris, 1989, 91p. (RD)

CHAVES, Femando de Oliveira. Algumas questões referentes à relação entre tecnologia e arte na história da fotografia. In: CORREA, Tupã Gomes, Org. Comunicação para o mercado: instituições, mercado, publicidade. São Paulo: Edicon, 1995. p.235-242. (HF)

CHERMONT, Solange de Campos. Considerações em torno do postal. Imagens e Igrejas da Vingem Maria através do postal. Recife: Fundação Joaquim Nabuco, 1983. (Catálogo de exposição). (HF) Fonte:MIRANDA, Victorino Coutinho Chermont de. A memória paraense no cartâo postal (1900-1930). Rio de Janeiro: Ed. Liney, 1986. 156p. 
CORDEIRO, Rosa Inês de Novais. Descrição e representação de fotografias de cenas e fotografas de filmes: esquema facetado e em níveis. Rio de Janeiro, 1990. Dissertação (Mestrado) - Centro de Filosofia e Ciências Humanas, Universidade Federal do Rio de Janeiro. (PT)

COSTA, Helouise. Aprenda a ver as coisas: fotojornalismo e modernidade na Revista O Cruzeiro. São Paulo, 1992. 190p. Dissertação (Mestrado) - Escola de Comunicações e Artes, Universidade de São Paulo. (HF, sh)

Da fotografia de imprensa ao fotojornalismo. Acervo - Revista do Arquivo Nacional, Rio de Janeiro, v.6, n.1-2, p. 75-86, jan.-dez. 1993. (HF)

Entrando por uma porta lateral ... In: FOTO A experiência alemã dos anos 50 GRAFLA . São Paulo: AS Studio, 1995. nâo pag. (Catálogo de exposição) (HF, rd)

. Fragmentos urbanos: a imagem da cidade na fotografia moderna brasileira dos anos 50. Anais do V Congresso Brasileiro de História da Arte, São Paulo, Comitê Brasileiro de História da ArteECA/USP, 1995, p.241-244. (HF)

Pictorialismo e imprensa: o caso da Revista O Cruzeiro (1928-1932). In: FABRIS, Annateresa, Org. Fotografia: usos e funções no século XIX. São Paulo: Edusp, 1991, p.261-292. (HF)

- Um olhar que aprisiona o outro: o retrato do índio e o papel do fotojornalismo na Revista $O$ Cruzeiro. Imagens, Campinas, n.2, p. 83-91, ago 1994. (SH, hf)

COSTA, Helouise; RODRIGUES, Renato. A fotografia modema no Brasil. Rio de Janeiro: Ministério da Cultura; Funarte/IPHAN, 1996. (HF)

COUTO, Ronaldo Graça, Org. A marinba por Marc Ferrez: 1880-1910. Rio de Janeiro: Index/Verolme, 1986, 120p. (RD, hf)

CPDOC/FUNDAÇÃO GETÚlIO VARGAS. Getúlio Vargas: 1983. Exposição de fotografias (19 abr. - 22 maio 1983). Rio de Janeiro: MAM/RJ, 1983. (Catálogo de exposição). (RD)

Procedimentos técnicos em arquivos privados. Rio de Janeiro: FGV/Cpdoc, 1986. (PT)

CUNHA, Manuela Carneiro da. Olhar escravo, ser olhado. In: AZEVEDO, Paulo Cesar de; UISSOVSKY, Maurício, Org. Escravos brasileiros do século XIX na fotografia de Cbristiano Jr. São Paulo: Ex-Libris, 1988, p.23-30. (SH)

CURNIER, Jean-Paul. A fotografia: memória de ruínas. Imagens, Campinas, n.3, p.103-106, dez. 1994. (TM)

DAYRELL, Antônio. Orientação para o processamento e conservação de fotografias em preto $e$ branco, com vistas à sua máxima permanência. Brasilia: Universidade de Brasilia, 1977, 15p. (Relatório técnico/Centro Nacional de Referência Cultural, 23) (PT) 
DE TACCA, Fernando. Fotografia e olhar totalitário. Imagens, Campinas, n.4, p.99-105, abr. 1995. (SH)

DEPARTAMENTO DO PATRIMÔNIO HISTÓRICO/SMC-SÃO PAULO. Guia preliminar do Arquivo de Negativos. São Paulo: DPH/SMC-SP, 1992, 40p. (RD)

O acervo fotográfico do Departamento do Patrimônio Histórico: processamento técnico e informatização. São Paulo: DPH/SMC-SP, 1992, 80p. (Coleções em Museus) (PT)

DIÁRIO DO GRANDE ABC: 25 ANOS DE FOTOJORNALISMO. S.1.: Diário do Grande ABC, 1983. (RD) Fonte: informação/Livros. IRIS, n. 362, p.11, ago.1983 (nota)

DIAS, Odete da Conceição. O trabalbador no discurso fotográfico do jornal "A Gazeta", 1930-1945. São Paulo, 1993. 196p. Dissertação (Mestrado) - Faculdade de Filosofia, Letras e Ciências Humanas, Universidade de São Paulo. (SH)

DOURADO, Odete. A documentação fotográfica e o inventário de proteção ao Acervo Cultural a experiência baiana. In: MUSEU DA IMAGEM E DO SOM. I Encontro de Fotografia e Memória Nacional. São Paulo: Secretaria da Cultura, 1981, p.85-90. (RD)

DUARTE, B. J.; HIRATA, Jorge. Ensaio fotográfico. Revista do Arquivo Municipal, São Paulo, p.7699, 1984. Edição comemorativa do cinquentenário da Revista do Arquivo Municipal. (RD)

DUFRICHE, Carlos E. Os aviões que fizeram a Aviação Comercial Brasileira. Rio de Janeiro: Sindicato Nacional dos Aeronautas, 1982. 155 p. (RD)

DUNCAN, Emília Beatriz. Histórico da seção iconográfica e cartográfica do Arquivo Nacional. Rio de Janeiro: Arquivo Nacional, 1982. (ms) (RD)

DUNLOP, Charles Julius. Álbum do Rio Antigo. Rio de Janeiro: Rio Antigo Ltda, 1965. 83p. (RD) Rio Antigo. Rio de Janeiro: Laemmert, 1955. 3v. (RD)

DUPRAT, Cecília. Revert Henrique Klumb: fotógrafo da família imperial brasileira. Annais da Biblioteca Nacional, Rio de Janeiro, v.102, não pag., 1982.(HF)

EASTMAN KODAK CO. Presenvação e remoção do mofo de filmes revelados. São Paulo: Kodak, s.d. (PT)

EGYPTO, Ednaldo. Quarenta anos do teatro paraibano. João Pessoa: Sed/Secetur, 1988. (RD)

ELETROPAULO. A cidade da Light: 1899-1930. São Paulo: Eletropaulo, 1990. 2v. (Coleção Memória, 1). (RD)

ENTLER, Ronaldo. A fotografia e o acaso. Campinas, 1994. 172p. Dissertação (Mestrado) - Instituto de Artes, Universidade Estadual de Campinas. (TM) 
ESSUS, Ana Maria Mauad de Souza Andrade. Sob o signo da imagem. Rio de Janeiro, 1990. Tese (Doutorado) - Universidade Federal Fluminense. (SH)

ESSUS, Ana Maria Mauad de Souza Andrade; GRINBERG, Lúcia. O século faz cinquenta anos: fotografia e cultura política. Revista Brasileira de História, São Paulo, v.14, n.27, p.129-148, 1994. $(\mathrm{SH})$

ESSUS, Ana Maria Mauad de Souza Andrade. O Olho da história: análise da imagem fotográfica na construção de uma memória. Acervo - Revista do Arquivo Nacional, Rio de Janeiro, v.6, n.1-2, p.25-40, jan.-dez. 1993. (SH)

FÁBRICA e Arredores: a FIAT nas fotografias de seu arquivo 1899-1960. São Paulo: s.c.p., 1992 93p. (RD)

FABRIS, Annateresa. A fotografia e a reprodutibilidade da obra de arte. Arte em São Paulo, São Paulo, n.12, não pag., nov. 1982. (HF)

A fotografia e o sistema de artes plásticas. In: FABRIS, Annateresa, Org. Fotografia: usos e funções no século XIX. São Paulo: Edusp, 1991, p.173-198. (HF, tm)

. A fotografia oitocentista ou a ilusão da objetividade. Porto Arte, Porto Alegre, v.5, n.8, p.1617, 1993. (HF)

A invenção da fotografia: repercussões sociais. In: FABRIS, Annateresa, Org. Fotografia: usos e funções no século XIX. São Paulo: Edusp, 1991, p.11-37. (HF)

O circuito social da fotografia: estudo de caso - I. In: FABRIS, Annateresa, Org. Fotografia: usos e funções no século XIX. São Paulo: Edusp, 1991, p.39-57. (HF)

FARIAS, Arion. Paraíba ontem e boje. Ed. Universitária da UFPB, 1985. 55p. (RD)

FATORELl, Antônio Pacca. A fotografia. Rio de Janeiro, 1991. 129p. Dissertação (Mestrado) Centro de Filosofia e Ciências Humanas, Universidade Federal do Rio de Janeiro. (HF, tm)

FELIPE, Paulo Duque Estrada. A imagem do espetáculo: aspectos da fotografia de teatro. Niterói, 1992. Dissertação (Bacharelado) - Universidade Federal Fluminense. (HF)

FERRARI, Sandro. A Coleção Família Brandão. Boletim do Centro de Memória da Unicamp, Campinas, v.5, n.10, p.103-110, jul.-dez. 1993. (PT, hf, rd)

FERREZ, Gilberto. Velhas Fotografias Pernambucanas, 1851-1890. 2.ed. Rio de Janeiro: Campo Visual, 1988. 90p. (RD, hf)

. A Avenida Central e seu álbum. In REGISTRO fotográfico de Marc Ferrez da construção da Av. Rio Branco, 1903-1906. Rio de Janeiro: Museu Nacional de Belas Artes, 1982, p.10. (Catálogo de exposição). (RD, hf) 
A fotografia no Brasil e um de seus mais dedicados servidores: Marc Ferrez (1843-1923). Revista do Patrimônio Histórico e Artístico Nacional. Rio de Janeiro, v.100, n.10, p. 169-304, 1946. (HF)

A Praça 15 de Novembro antigo Largo do Carmo. Rio de Janeiro: RioTur Empresa de Turismo do Município do Rio de Janeiro, 1978. 68p. (RD)

. Ferrez por Ferrez. In: COUTO, Ronaldo Graça, Org. A Marinba por Marc Ferrez: 1880-1910. Rio de Janeiro: Index/Verolme, 1986, p.9-12. (HF)

Fotografia no Brasil: 1840-1900. 2.ed. Prefácio Pedro Vasquez. Rio de Janeiro: Funarte/PróMemória, 1985. 248p. (HF, rd)

Iconografia Petropolitana (1800-1890). Rio de Janeiro: Museu Imperial, 1955. (RD)

. Marc Ferrez. Zoom Spécial Brésil. Paris, v.2 , n.121, não pag., 1986. (HF) Fonte: VASQUEZ, Pedro. Aspectos da fotografia brasileira no século dezenove. Rio de Janeiro: MAM/Depto. de Fotografia, Vídeo \& Novas Tecnologias, 1987. 37p. (Catálogo de exposição)

O Paço da cidade do Rio de Janeiro. Rio de Janeiro: Fundação Nacional Pró-Memória, 1985. 82p. (RD)

Photography in Brazil: 1840-1900. Albuquerque: University Of New Mexico, 1990. 243p. (HF, rd)

. Um passeio a Petrópolis em companhia do fotógrafo Marc Ferrez. Anuário do Museu Imperial. Petrópolis, 1951. Separata. (RD)

FERREZ, Gilberto; MATTOSO, Kátia M. Queirós. Babia: velhas fotografias, 1858-1900. Rio de Janeiro: Kosmos, 1988. (RD)

FERREZ, Gilberto; NAEF, Weston J. Pionner photographers of Brasil: 1840-1920. New York: Center for Inter-American Relations, 1976, 143p. (HF, rd)

FERREZ, Gilberto; VASQUEZ, Pedro. A fotografia no Brasil do século XIX: 150 anos do fotógrafo Marc Ferrez 1843/1993. São Paulo: Pinacoteca do Estado, 1993. 64p. (RD)

_. Fotografia no Brasil: 1840-1920. 2.ed. Rio de Janeiro, Funarte, 1985. (HF, rd)

FERREZ, Marc; FERREZ, Gilberto. O Rio antigo do fotógrafo Marc Ferrez: paisagens e tipos humanos do Rio de Janeiro, 1865-1918. Prefácio Pedro Nava. São Paulo: Ex-Libris; João Fortes Engenharia, 1984. (RD, hf)

FERREZ, Marc; FERREZ, Gilberto; SANTOS, Paulo F. O álbum da Avenida Central: um documento fotográfico da construçâo da Avenida Rio Branco; Rio de Janeiro, 1903-1906. Rio de Janeiro: João Fortes Engenharia/Ex-Libris, 1982. 241p. (RD) 
FLORENCE, Arnaldo Machado. A fotografia é uma invenção brasileira. FURB. Revista de Divulgação Cultural, Blumenau, Ano 4, n.15, p. 23, dez 1981. (HF)

FLORENCE, Arnaldo Machado. A invenção da fotografia uma glória do Brasil. Foto Cine, São Paulo, v.212, p. 5-10, fev. 1977. (HF) Fonte: Bibliografia Temática. Boletim do Centro de Memória da UNICAMP, Campinas, v.5, n.10, jul.-dez. 1993, p.131-142.

. Hercules Florence: o pioneiro da fotografia. a descoberta da fotografia em 1832. Boletim: Foto Cine Clube Bandeirante, São Paulo, ano III, n. 27/28, p. 27-28/4-10/15-16, jul.-ago. 1948. (HF)

FLORES, Moacyr. A iconografia do negro no Rio Grande do Sul. In: MUSEU DA IMAGEM E DO SOM. I Encontro de Fotografia e Memória Nacional. São Paulo: Secretaria da Cultura, 1981, p.147-151. (RD)

FLUSSER, Vilém. Filosofia da fotografia. Arte em São Paulo. São Paulo, n.21, não pag., mar. 1984. (TM)

Filosofia da caixa preta: ensaios para uma futura filosofia da fotografia. São Paulo: HUCITEC, 1985.(TM)

FOTÓPTICA. Fotografia e os Anos 70. São Paulo: Fotóptica, MAC/USP, 1985. (Catálogo de exposição). (RD)

FOTÓPTICA. Fotografia e os Anos 60. São Paulo: Fotóptica, MAC/USP, 1985. (Catálogo de exposição) (RD). Fonte: COSTA, Helouise; RODRIGUES, Renato. A fotografia moderna no Brasil. Rio de Janeiro: Ministério da Cultura; Funarte/IPHAN, 1996. (HF)

FRAYZE-PEREIRA, João A. Sobre o mistério da fotografia. Arte em São Paulo, São Paulo, n.17, não pag., jul.-ago. 1983. (TM)

FREYRE, Gilberto. Em torno da sociofotografia. Rio de Janeiro: Funarte, 1984. (TM)

Informação, comunicação e cartão-postal. In: Fronteira, 1978, p.147-161. (TM)

. Por uma sociofotografia. In: O retrato brasileiro: fotografias da Coleçâo Francisco Rodrigues 1840-1920. Rio de Janeiro: Funarte/Fundação Joaquim Nabuco, 1983. p.15-24. (TM)

FRÓES, Leonardo, OLIVEIRA, Mariliah de Castro, TRINDADE, Lena. Coisas nossas: os lambelambes. Rio de Janeiro: Depto de Cultura/ Inst. Est. do Livro/Funarte, 1978. (HF)

FRÓES, Leonardo. Lambe-Lambe. Rio de Janeiro; Secretaria da Educação e Cultura, 1978. (HF)

FUNARTE. Arquivo fotográfico: estudo preliminar. Rio de Janeiro: Funarte, 1982. 129p. (PT) . Camaval de Malta . Rio de Janeiro: Funarte, 1980. 48p. (Mostra Fotográfica). (RD) . José Medeiros: 50 anos de fotografia. Rio de Janeiro: Funarte/Infoto, 1986. (Catálogo de exposição). (RD) 
. Proposta para uma política nacional de fotografia. Rio de Janeiro: Funarte/InFoto, 1986. 19p. (PT)

Revolução de 30. Rio de Janeiro: Funarte, 1980. (RD)

Revolução de 32: a fotografia e a política. Rio de Janeiro: Funarte, 1982. 60p. (RD)

FUNARTE/IBAC et. al. Manual para catalogação de documentos fotográficos: versão preliminar. Rio de Janeiro: Funarte-IBAC/Fundação Biblioteca Nacional/Museu Histórico Nacional/Museu Imperial de Petrópolis/Cpdoc-FGV, 1993. (PT)

FUNARTE/MOSTRA DE FOTOGRAFIA. Herminia de Mello Nogueira Borges: fotografias das décadas de 20 a 40. Rio de Janeiro: Funarte/Núcleo de fotografia, 1981. 48p. (RD)

FUNDAÇÃO DO CINEMA BRASILEIRO. Manual arquivo fotográfico FCB. Rio de Janeiro: Ministério da Cultura/Fundação do Cinema Brasileiro, s.d. (Série Documentos, 5). (PT)

FUNDAÇÃO JOÃO PINHEIRO. Manual de orientação para preservação de acervos fotográficos. Belo Horizonte: Fundação João Pinheiro/UFMG, 1985. 43p. (PT)

FUNDAÇÃO JOAQUIM NABUCO. O negro ontem e boje: catálogo da exposição iconográfica. Recife: Galeria Vicente do Rego Monteiro/INAC, 1988. 36p. (RD)

. O sujeito em perigo: identidade fotográfica e alteridade no Brasil do século XIX até 1940. Recife: FUNDAJE/Ed. Massangana, 1992. 52p. (SH)

GILSON, Etienne. Fotografia e beleza. Diógenes, Brasília, v.6, p.19-34, 1984. (TM)

GLASURIT. Paço dos Açorinos: sede da Prefeitura Municipal de Porto Alegre. São Paulo: Iconographia/Glasurit, s.d. 18p. (RD)

GONÇALVES, Cássia Denise; LEÃO, Flávia Carneiro. Os retalhos fotográficos de Geraldo Sesso Jr. Boletim do Centro de Memória da Unicamp, Campinas, v.5, n.10, p.89-100, jul.-dez. 1993. (PT)

GORDINHO, Margarida Cintra; MONTEIRO, Sylvia. Gaspar Gasparian: um fotógrafo paulista. São Paulo: Marca D’Água, 1988. (RD)

GORENDER, Jacob. A face escrava da Corte Imperial Brasileira. In: AZEVEDO, Paulo Cesar de; LISSOVSKY, Maurício, org. Escravos brasileiros do século XLX na fotografia de Christiano Jr. São Paulo: Ex-Libris, 1988, p.31-36. (SH)

GOULART, Paulo Cezar Alves; MENDES, Ricardo (colab.). Noticiário geral da pbotograpbia paulistana: 1839-1900. São Paulo: SMC/CCSP/Div. Pesquisas, 1993. 167p. (ms) (HF)

GRANGEIRO, Cândido Domingues. As artes de um negócio: a febre photographica. São Paulo 18621886. Campinas, 1993. 266p. Dissertação (Mestrado), Universidade Estadual de Campinas. (HF) 
GRINBERG, Isaac. Memória fotográfica de Mogi das Cruzes. São Paulo: Ex-Libris, 1986. (RD)

GUIDI, Mário Arturo Alberto. De Altamira a Palo Alto: a busca do movimento. São Paulo, 1991. Tese (Livre-Docência) - Escola de Comunicações e Artes, Universidade de São Paulo. (HF, tm)

GUIMARÃES, Marco Antônio Campos. Madeira-Mamoré. In: MUSEU DA IMAGEM E DO SOM. I Encontro de Fotografia e Memória Nacional. São Paulo: Secretaria da Cultura, 1981, p.23-25. (RD)

GURAN, Milton. Linguagem fotográfica e informação. Rio de Janeiro: Rio Fundo, 1992. 113p. (HF)

HABERT, Angeluccia Bernardes. Fotonovela e indústria cultural. Petrópolis: Vozes, 1974. (SH)

HARDMAN, Francisco Foot. Os negativos da história: a ferrovia-fantasma e o fotógrafo cronista. Resgate, Campinas, n.5, p. 9-21, 1993. (SH, hf)

HERKENHOFF, Paulo. Fotografia: o automático e o longo processo de modernidade. In: TOLIPAN, Sérgio et al. Sete ensaios sobre o modemismo. Rio de Janeiro: Funarte/Instituto Nacional de Artes Plásticas, 1983, p.39-46 (Cadernos de Textos, 3) (HF)

HOMEM, Maria Cecilia Naclério. Visão urbana: o pioneirismo de Amélia Sabino de Oliveira ao registrar São Paulo nos anos 30. Memória, São Paulo, ano V, n.19, p.11-13, jul.-dez. 1993. (HF)

HUMBERTO, L. Fotografia: universo e arrabaldes. Rio de Janeiro: Funarte/Instituto Nacional de Fotografia, 1983. (TM, hf)

ICONOGRAFIA de Joaquim Nabuco. Recife: IJNPS/MEC/DAC, 1975. (Série Documentos, 2) (RD)

INSTITUTO CULTURAL ITAÚ. Avenida Paulista. São Paulo: Instituto Culnural Itaú, 1993. 35p. (Cadernos cidade de São Paulo II, 8). (RD)

Bairno dos Campos Elíseos. São Paulo: Instituto Cultural Itaú, 1995. 31p. (Cadernos cidade de São Paulo, 12). (RD)

. Estádios. São Paulo: Instituto Cultural Itaú, 1994. 40p. (Cadernos cidade de São Paulo, 10). (RD)

Largo da Memória. São Paulo: Instituto Cultural Itaú, 1993. 23p. (Cadernos cidade de São Paulo, 6). (2.ed. rev. amp, 1994, 27p.). (RD)

Largo São Bento, Viaduto Santa Efigênia, Largo Santa Efigênia. São Paulo: Instituto Cultural Itaú, 1993. 24p. (Cadernos cidade de São Paulo, 3). (2.ed. rev. amp., 1994, 29p.). (RD) 
Parque da Independência. São Paulo: Instituto Cultural Itaú, 1993. 23p. (Cadernos cidade de São Paulo, 7). (2.ed. rev. amp., 1994, 29p.). (RD)

Pátio do Colégio. São Paulo: Instituto Cultural Itaú, 1993. 23p. (Cadernos cidade de São Paulo, 2). (2.ed. rev. amp., 1994, 41p.). (RD)

Praça da República. São Paulo: Instituto Cultural Itaú, 1995. 31p. (Cadernos cidade de São Paulo, 13). (RD)

Praça da Sé. São Paulo: Instituto Cultural Itaú, 1993. 23p. (Cadernos cidade de São Paulo, 4). (2.ed. rev. amp., 1994, 29p.). (RD)

Praça Ramos, Viaduto do Chá, Praça do Patriarca. São Paulo: Instituto Cultural Itaú, 1992. 19p. (Cadernos cidade de São Paulo, 1). (2.ed. rev. amp., 1994, 35p.). (RD)

Região da Luz. São Paulo: Instituto Cultural Itaú, 1994. 32p. (Cadernos cidade de São Paulo II, 9). (RD)

Região Tiradentes. São Paulo: Instituto Cultural Itaú, 1994. 34p. (Cademos cidade de São Paulo, 11). (RD)

INSTITUTO GEOGRÁFICO E CARTOGRÁFICO, org. Coleção de aerofotos oblíquas do IGC: 1939-1940. São Paulo: IGC, 1993. 63p. (RD)

INSTITUTO GEOGRÁFICO E HISTÓRICO DO AMAZONAS, org. Manaus: memória fotográfica. Manaus: SUFRAMA, 1985. 106p. (RD)

INSTITUTO NACIONAL DE FOTOGRAFIA. Montagem de exposições fotográficas: guia de normas básicas. Rio de Janeiro: Infoto, 1986. 10p. (PT)

INVENTÁRIO E PROTEÇÃO DO ACERVO CULTURAL. Vila Casoni: retratos de um bairro londrino. Londrina: IPAC, 1988. (RD)

JOBIM, Elianne Andrea Canetti. O risco e o olhar: sobre a imagem da cidade do Rio de Janeiro. Gávea - Revista de História da Arte e Arquitetura, Rio de Janeiro, p.74-79, dez. 1991. (SH)

KLEEMANN, Fredi; MARCONDES, Tânia; VARGAS, Maria Thereza. Foto em cena. São Paulo: Secretaria Municipal de Cultura, 1991. (RD)

KLINTOWITZ, Jacob. A arte do comércio II: São Paulo 1930-1954. São Paulo: SENAC, 1989. 217p. $(\mathrm{RD})$ A arte do comércio III: São Paulo 1954-1991. São Paulo: SENAC, 1991. 217p. (RD) A arte do comércio: São Paulo 1900-1930. São Paulo: SENAC, 1988. 217p. (RD) 
KOSSOY, Boris; CARNEIRO, Maria Luiza Tucci . O negro na iconografia brasileira do século XIX: a visão européia. São Paulo: FFLCH/USP, 1988. (Catálogo de exposição). (RD)

O olhar europeu: o negro na iconografia brasileira do século XIX. São Paulo: Edusp, 1994, 235p. (RD)

KOSSOY, Boris. Elementos para o estudo da fotografia no Brasil no século XIX. São Paulo, 1979. Tese (Doutorado) - Faculdade Escola de Sociologia e Políica de São Paulo. (HF)

Hercules Florence, 1833: a descoberta isolada da fotografia no Brasil. 1.ed. São Paulo: Faculdade De Comunicação Anhembi, 1976. 108p. (2.ed. aumentada em 1980 pela Duas Cidades). (HF)

Militão Augusto de Azevedo e a documentação fotográfica de São Paulo (1862- 1887): recuperação da cena paulistana através da fotografia. São Paulo, 1978. 121p. Dissertação (Mestrado) - Faculdade Escola de Sociologia e Política de São Paulo. (HF)

A fotografia como fonte histórica: introdução à pesquisa e interpretaçâo das imagens do passado. São Paulo: Museu da Indústria, Comércio e Tecnologia, 1980. (TM)

A fotografia: um documento estético-social. Cultura, Brasília, v.2, n.8, p.26-39, out.-dez. 1972. (HF)

. Álbum de photographias do Estado de São Paulo 1892: estudo crítico. São Paulo: Kosmos, 1984. (RD)

Elementos para el desarrollo de la historia de la fotografia en America Latina. Memorias del Primer Coloquio Latino-Americano de fotografia. México, Consejo Mexicano de Fotografia, 1978, 21p. (HF) Fonte: Bibliografia Temática. Boletim do Centro de Memória da UNICAMP, Campinas, v.5, n.10, jul.-dez. 1993, p.131-142.

Estética, memória e ideologia fotográficas. decifrando a realidade interior das imagens do passado. Acervo - Revista do Arquivo Nacional, Rio de Janeiro, v.6, n.1-2, p.13-24, jan.-dez. 1993. (TM)

Fotografia e História. São Paulo: Ática, 1989. (Coleção Princípios, 176). (TM)

Fotografia. In: ZANINI, Walter, org. História geral da arte no Brasil. São Paulo: Instituto Walther Moreira Salles/Fundação Djalma Guimarães, 1983. v.2, p.867-913. (HF)

Fotografia: câmaras e aparelhos de dois séculos. São Paulo: Secretaria de Estado da Cultura de São Paulo/Museu da Imagem e do Som/Museu Foto-Hitorama de Agfa-Gevaert, 1981. (Catálogo de exposição). (HF)

Hercules Florence: pioneer of photography in Brazil. New York: s. e., 1976. (ms). (HF) Fonte: Memória da UNICAMP, Campinas, v.5, n.10, jul.-dez. 1993, p.131-142. (Catálogo de exposição) 
La photo brésilienne au XXIe siècle. Zoom Spécial Brésil, Paris, v.2, n.121, 1986. (HF) Fonte: VASQUEZ, Pedro. Aspectos da fotografia brasileira do século dezenove. Rio de Janeiro: MAM/Depto. de Fotografia, Vídeo \& Novas Tecnologias, 1987. 37p.

Militão Augusto de Azevedo of Brasil, the photographic documentation of Sao Paulo (18621887). History of Photography, New York, v.4, n.1, 1980. (HF)

O papel do MIS na preservação do patrimônio cultural brasileiro. In: MUSEU DA IMAGEM E DO SOM. I Encontro de Fotografia e Memória Nacional. São Paulo: Secretaria da Cultura, 1981, p.157-167. (PT)

_. O poder da imagem. Memória, Rio de Janeiro, v.3, n.6, p.58, jan.-fev.-mar. 1990. (TM)

Origens e expansão da fotografia no Brasil; século XIX. Rio de Janeiro: Funarte, 1980. (HF)

. Panorama da fotografia no Brasil desde 1832. Comunicação, São Paulo, v.1, n.1, p.19-50, out. 1976. (HF)

—. São Paulo, 1900. São Paulo: CBPO/Kosmos, 1988. (RD)

KUBRUSLY, Cláudio A. O que é fotografia. São Paulo: Brasiliense, 1983. 109p. (Coleção Primeiros Passos, 82) (HF)

LACERDA, Aline Lopes de. A obra getuliana ou como as imagens comemoram o regime. Estudos Históricos, Rio de Janeiro, v.7, n.14, p. 241-263, 1994. (SH)

Os sentidos da imagem: fotografias em arquivos pessoais. Acervo - Revista do Arquivo Nacional, Rio de Janeiro, v.6, n.1-2, p. 41-54, jan-dez 1993. (PT)

LAURITO, Ilka Brunhilde. Retratos de um photographo. In: SÃO PAULO. São Paulo em três tempos: álbum comparativo da cidade de São Paulo (1862-1887-1914). São Paulo, IMESP, 1982, p.9-19. (HF)

LAVENÈRE, L. \& SANT'ANNA, Moacir Medeiros de. A fotografia em Maceió (1858-1918). Revista do Arquivo Público de Alagoas, Maceió, n.1, p.119-150, 1962. (HF)

LEITE, Miriam L. Moreira. A imagem através das palavras. Ciência e Cultura., v. 7, n. 38, p.1.4831.495, set. 1986. (TM) Ainda retratos de familita. Reunião Anual da ABA, 19, 1994, Niterói. (Comunicação). (SH) Fotografia \& História. Ciência Hoje, s.l. v.7, n.39, p.24-32, jan.fev., 1988. (SH)

Fotografias de familia: potencialidades e limitações da documentaçâo fotográfica. Cadernos CERU, São Paulo, n.18, p.79-89, maio 1983. (SH) 
. História e Fotografia. Cultura Vozes, São Paulo, v.86, n.3, p.43-52, maio-jun. 1992. (SH, tm)

- Imagens e contextos. Boletim do Centro de Memória da Unicamp, Campinas, v.5, n.10, p.4560, jul.-dez. 1993. (SH)

_.. O imaginārio das famílias. Reunião Anual da ABA, 19, 1994, Niterói. (Comunicação). (SH)

. O retrato de casamento. Novos Estudos, CEBRAP, n.29, p.182-189, mar. 1991. (SH)

. Retrato de casamento. Literatura e Memória Cultural: Anais, v.1. Belo Horizonte, Abralic, 1991, p.335-351. (SH)

Texto Visual E Texto Verbal. Reunião Anual da ANPOCS, 17, 1993, Caxambu (Comunicação). (SH)

. Utilização da documentação fotográfica. Ciência Hoje, São Paulo, n.39, jan.fev. 1988. (TM)

Retratos de família: leitura da fotografia histórica. São Paulo: Edusp, 1993. (SH)

LEITE, Miriam L. Moreira; SIMSOM, Olga R. M. Von. Imagem e linguagem: reflexões de pesquisa. Texto CERU, São Paulo, série 2, n.3, p.117-140, 1992. (TM)

LEMOS, Carlos A. C. Ambientação ilusória. In: MOURA, Carlos Eugênio Marcondes de, org. Retratos quase inocentes. São Paulo: Nobel, 1983, p.47-113. (SH)

Metamorfose paulistana. In: SÃO PAULO. São Paulo em três tempos: álbum comparativo da cidade de São Paulo (1862-1887-1914). São Paulo: IMESP, 1982. p.21-29. (HF)

LEVI- STRAUSS, Claude; MENDES, Ricardo. Saudades do Brasil. São Paulo: Cia das Letras, 1994, 227p. (RD)

. Saudades de São Paulo. São Paulo: Nova Fronteira, 1996. (RD)

LIMA, Mariângela Muraro Alves de, org. Imagens do teatro paulista. São Paulo: Imprensa Oficial do Estado/CCSP, 1985, 288p. (RD)

LIMA, Michael Roberto Alves de. Manual básico de processamento fotográfico em branco e preto visando a longa permanência, Revista da Biblioteca Mário de Andrade, São Paulo, n.5, p.113-123, jan-dez 1994. (PT)

LIMA, Solange Ferraz de. São Paulo na virada do século: as imagens da razão urbana - a cidade nos álbuns fotográficos de 1887 a 1919. São Paulo, 1995. 283p. Dissertação (Mestrado) - Faculdade de Filosofia, Letras e Ciências Humanas, Universidade de São Paulo. (SH)

. Espaços projetados: as representações da cidade de São Paulo nos álbuns fotográficos do início do século. Aceno - Revista do Arquiıo Nacional, Rio de Janeiro, v.6, n.1-2, p. 99-110, jan-dez 1993. (SH) 
O circuito social da fotografia: estudo de caso - II. In: FABRIS, Annateresa, org. Fotografia: usos e funções no século XIX. São Paulo: Edusp, 1991, p. 59-82. (HF)

LISSOVSKY, Maurício. O dedo e a orelha: ascensão e queda da imagem nos tempos digitais. Acervo Revista do Arquivo Nacional, Rio de Janeiro, v.6, n.1/2, p. 55-74, jan-dez 1993 (SH, tm)

LISSOVSKY, Maurício; AZEVEDO, Paulo César (orgs.). Escravos brasileiros do século XIX na fotografia de Christiano Jünior. São Paulo: Ex-Libris, 1988. (RD)

LOBO, Lúcia Lahmeyer. Avaliação e seleção de fotografias. Arquivo \& Administração, Rio de Janeiro, v. 1, ns.10-14, p. 34- 40, abr 1982/ ago 1986. (PT)

LOBO, Lúcia Lahmeyer; BRANDÃO, Ana Maria de Lima; LISSOVSKY, Maurício. A fotografia como fonte histórica: a experiência do Cpdoc. Acervo - Revista do Arquivo Nacional, Rio de Janeiro, v.2, n.1, p. 30-52, jan-jun, 1987. (TM)

LOPEZ, Telê Porto Ancona. Fotógrafo e o Turista Aprendiz. In: Mário de Andrade: fotógrafo e turista na Amazônia. São Paulo: Associação Pró-Parque Modernista/IEB-USP, 1990, p.6-18 (Catálogo de exposição) (SH)

Viagens e o fotógrafo. In: ANDRADE, Mário de. Mârio de Andrade: fotógrafo e turista aprendiz. São Paulo: Instituto de Estudos Brasileiros, 1993, p.109-120. (SH)

Viagens etnográficas de Mário de andrade: itinerário fotográfico. Revista do Instituto de Estudos Brasileiros, São Paulo, n.11, p. 139-174, 1972. (RD, sh)

MACHADO, Arlindo. A fotografia sob o impacto da eletrônica. In: MACHADO, Arlindo. Ensaios sobre a contemporaneidade. São Paulo: Núcleo de Linguagens Visuais da PUC/SP, 1994. 242p. (TM)

A ilusão especular: introdução à fotografia. São Paulo/Rio de Janeiro: Brasiliense/Instituto Nacional da Fotografia, 1984. Originalmente Dissertação (Mestrado) (TM, hf)

As imagens técnicas: da fotografia à síntese numérica. Imagens, Campinas, n.3, p. 8-14, dez 1994. (TM)

MARQUES, Mário Osório. História visual da formação de Ijui, Rio Grande do Sul. Ijuí: Unijuí Editora, 1990. (Coleção Centenário de Ijuí, 7) (RD, tm, sh)

MASCARO, Cristiano. A fotografia e a arquitetura. São Paulo, 1994.. Tese (Doutorado) - Faculdade de Arquitetura e Urbanismo, Universidade de São Paulo. (HF, tm)

MAZZA, Márcio Lucas Gimenez. Lambe-lambe em São Paulo. São Paulo, 1974. Tese (Graduação) Faculdade de Arquitetura e Urbanismo, Universidade de São Paulo. (HF)

MEDEIROS, Humberto Pereira. A imagem fotográfica e suas construções: fotoclubismo e fotojornalismo comparados. Rio de Janeiro, s.d. 68p. Dissertação (Mestrado) - Centro de Filosofia e Ciências Humanas, Universidade Federal do Rio de Janeiro. (HF) 
MEDINA, José. São Paulo, o que foi e o que é. s.l.: s.e., 1954. (RD)

MEIRELLES, Willian Reis. História das imagens: uma abordagem, múltiplas facetas. Pós-História, Assis, n. 03, p. 93-103, 1995. (TM)

MELLO, Márcia; PESSOA, Maristela. Manual de acondicionamento de material fotográfico. Rio de Janeiro: Funarte/IBAC, 1994. 32p. (PT)

MELLO, Maria Teresa Villela Bandeira de. Arte e fotografia: o movimento pictorialista no Brasil. Rio de Janeiro, 1994, 176p. Dissertação (Mestrado) - Centro de Filosofia e Ciências Humanas, Universidade Federal do Rio de Janeiro. (HF)

MELO, Francisco Inácio Homem de. Cidade, fotografia, tipografia. São Paulo, 1994. Tese (Doutorado) - Faculdade de Arquitetura e Urbanismo, Universidade de São Paulo. (SH)

MENDES, Ricardo. A Revista S.Paulo (1936): fotografia de paisagem e documentação urbana em uma sociedade de mídia visuais. Anais do V Congresso Brasileiro de História da Arte, São Paulo, Comitê Brasileiro de História da Arte-ECA/USP, 1995, p. 232-240. (SH)

A Revista S.Paulo: a cidade nas bancas. Imagens, Campinas, n.3, p. 91-97, dez 1994. (SH)

Descobrindo a fotografia nos manuais: América (1840-1880). In: FABRIS, Annateresa, org. Fotografia: usos e funções no século XIX. São Paulo: Edusp, 1991, p. 83-130. (HF)

MENDONÇA, Leila Lobo de. Iconografia da eletricidade no Brasil. Memória da Eletricidade, Rio de Janeiro, v.16, p. 3, dez 1990. (RD) Fonte: Bibliografia Temática. Boletim do Centro de Memória da UNICAMP, Campinas, v.5, n.10, jul.-dez. 1993, p.131-142.

MENDONÇA, Leila Lobo de; MARTINS, Gilberto Lima. Memória visual. Memória da Eletricidade, Rio de Janeiro, v.9, p. 5-6, jul 1989. (RD) Fonte: Bibliografia Temática. Boletim do Centro de Memória da UNICAMP, Campinas, v.5, n.10, jul.-dez. 1993, p.131-142.

MENDONÇA, Thaís de. A fotografia ganha seu instituto. Cultura, Brasília, v. 42, n.12, p. 22-27, jan-dez 1984. (RD) Fonte: Banco Bibliográfico sobre fotografia/ Div. de Pesquisa do Centro Cultural São Paulo.

MICHELON, Francisca Ferreira. Um estudo da metáfora visual nas séries fotográficas aqualis. Porto Alegre, 1993. Dissertação (Mestrado). Universidade Federal do Rio Grande do Sul. Fonte: Biblioteca do Instituto de Artes/UNICAMP.

MICHIDA, Milton Toshiyuki. Sintaxe do fotojornalismo: análise da 'foto' oficial de Tancredo Neves. In: SANTAELLA, Lúcia; OLIVEIRA, Ana Cláudia de, org. Semiótica da Comunicação e outras ciências. São Paulo: Educ/Fapesp, 1987, p.115-120. (Cadernos da Puc, 30) (SH)

MIGUEL, Maria Lúcia Cerutti. A fotografia como documento: uma instigação à leitura. Acervo - Revista do Arquivo Nacional, Rio de Janeiro, v.6, n.1-2, p. 121-132, jan-dez 1993. (TM) 
MIRANDA, Antônio. O que é cartofilia. Brasilia: Sociedade Brasileira de Cartofilia, 1985, 72p. (HF)

MIRANDA, Antônio; NOCETTI, Milton A. cartão postal e biblioteca: suporte à pesquisa. Revista Latina de Documentação. n.2 (2), 24-29, 1982. Fonte: MIRANDA, Victorino Coutinho Chermont de. A Memória Paraense No Cartão Postal (1900-1930). Rio de Janeiro: Ed: Liney, 1986, 156p.

MIRANDA, Victorino Coutinho Chermont de. A Memória Paraense No Cartão Postal (1900-1930). Rio de Janeiro: Ed. Liney, 1986. 156p. (RD, hf)

MORAES, Marcos Antônio de, org. "Tudo está tão bom, tão gostoso ..." postais a Mário de Andrade. São Paulo: Hucitec, 1993. 224p. (RD, hf)

MORAIS, Frederico. Realismo e imagem. Revista de Cultura Vozes, Ano 68, n.6, p.27-31, mai 1974. (TM)

MOREIRA FILHO, Alcindo. Apropriação de uma imagem do século XIX em processos fotomecânicos. ARTEunesp, São Paulo, n. 10, p.13-19, 1994. (TM)

MOTA, Mauro. Retratos do Recife. Arq. Recife, Recife, n. 1, p. 187-190, jan-jun,1976. (RD)

MOURA, Carlos Eugênio Marcondes de. Retratos quase inocentes. In: MOURA, Carlos Eugênio Marcondes de (org.). Retratos quase inocentes. São Paulo: Nobel, 1983, p.3-46. (HF)

MURAKAMI, Ana Maria Brandão et al. Cadastro de arquivos fotográficos existentes na cidade do Rio de Janeiro, em instituições privadas governamentais e particulares. Arquivos Fotográficos, Estudo Preliminar. Rio de Janeiro: Funarte, 1982. (PT)

MURAKAMI, Ana Maria Brandão. A Revolução de 1930 e seus antecedentes. Rio de Janeiro: Nova Fronteira/Fundação Getúlio Vargas, 1980. 213p. (RD)

MUSEU AEROESPACIAL. A bistória da aviação militar através da fotografia. Rio de Janeiro: Museu Aeroespacial, 1992. 268p. (RD, pt, hf)

MUSEU DA IMAGEM E DO SOM. Memória Paulistana. São Paulo: MIS/SP, 1975. (RD)

MUSEU DE ARTE DE SÃO PAULO. Coleção Pirelli de Fotografias de 1994. Texto de Zé de Boni A fotografia virou arte. São Paulo: MASP, 1994. (RD)

Coleção Pirelli de Fotografias de 1993. Texto de Thomas Farkas - Movimento Foto-Brasil. São Paulo: MASP, 1993. (RD)

. Coleção Pirelli de Fotografias de 1992. Texto de Rubens Fernandes Junior - Fotografia brasileira contemporânea: influências e repercussões. São Paulo: MASP, 1992. (RD)

Coleção Pirelli de Fotografias de 1991. Texto de Boris Kossoy - Memória da fotografia: o nascimento de uma coleção. São Paulo: MASP, 1991. (RD) 
Coleção Pirelli de Fotografias de 1995. São Paulo: MASP, 1995. (RD)

MUSEU HISTÓRICO DA IMAGEM FOTOGRÁFICA DA CIDADE DE SÃO PAULO. Projeto Museu de Rua: percursos centro histórico, história do Anhangabaú e do Viaduto do Chá, Memória da Sé. São Paulo: PMSP/SMC/DPH, 1979. 102p. (Registros, 3). (RD, hf)

MUSEU LASAR SEGALL. Fotografia Buraco de Agulha. São Paulo: Museu Lasar Segall, 1981. (Catálogo de Exposição). (HF)

Fotografia e documentação (O trabalbo de Herman Graeser). São Paulo: Museu Lasar Segall, 1981, 32p. (Catálogo de exposição). (RD, hf)

Lambe Lambe hoje: o fotógrafo de jardim. Sâo Paulo: MLS/Secretaria da Cultura do Governo do Estado de São Paulo, 1980. (Catálogo de exposição) (HF)

_. Segall através da fotografia. São Paulo: Museu Lasar Segall, 1982, 50p. (RD)

NEISTEIN, José. Fotografias brasileiras raras da Biblioteca Oliveira Lima. In: NEISTEIN, José. Feitura das artes. São Paulo: Perspectiva, 1981, p.115-116. (Coleção Debates) (PT)

NEIVA JÚNIOR, Eduardo. On photography, 'Sémiologie' and 'Sociologie'. Semiotica, s.l., v. 3/4, n. 91 , p. 371-381, 1992. (TM)

A imagem. São Paulo: Ática, 1986. 93p. (Coleção Princípios, 87) (TM)

OLIVA, Aloízio Mercadante, org. Imagens da luta: 1905-1985. São Bernardo: Sindicato dos Trabalhadores nas Indústrias Metalúrgicas, Mecânicas e de Material Elétrico, 1987, 272p. (RD)

OLIVEIRA JUNIOR, Antônio R. de. A fotografia oficial: imagem do poder. Boletim do Centro de Memória da Unicamp, Campinas, v.5, n.10, p. 33-42, jul-dez 1993. (TM)

Do reflexo à mediação: um estudo da expressão fotográfica e da obra de Augusto Malta. Campinas, 1994. Dissertação (Mestrado) - Instituto de Artes, Universidade Estadual de Campinas. (SH)

OLIVEIRA, João Sócrates de. Fotografia: arte e uso. São Paulo: MASP/KODAK, 1981. (PT)

Manual prático de preservação fotográfica. São Paulo: Museu da Indústria, Comércio e Tecnologia de São Paulo, 1980. 47p. (Museus \& Técnicas, 5). (PT)

OLIVEIRA, Márcia Ribeiro de. A memória fotográfica de São Paulo em processo de informatização. Acervo - Revista do Arquivo Nacional, Rio de Janeiro, v.6, n.1-2, p. 145-154, jan-dez 1993. (PT)

OLSZEWSKI FILHA, Sofia. A imagem do negro na cidade de Salvador: 1840-1914. Salvador: EGBA/Fundação Cultural do Estado da Bahia, 1989, 131p. Originalmente Dissertação (Mestrado) (SH) 
OHTAKE, Ricardo; GAGLIARDO, Cristina. A experiência do IDART. In: MUSEU DA IMAGEM E DO SOM. I Encontro de Fotografia e Memória Nacional. São Paulo, Secretaria da Cultura, 1981, p. 99-107. (PT)

PAES, Marilena Leite; MARQUES, Heloísa Helena Riani. Arquivos fotográficos. Arquivo $\mathcal{E}$ Administração, Rio de Janeiro, v.2, n.5, p.17-19, 1977. (PT)

PAIVA, Joaquim, org. Olbares refletidos: diálogo com 25 fotografos brasileiros. Rio de Janeiro: Dazibao, 1989. 255p. (HF)

PAULINO, Ana Maria. Fotografia, uma arte para Mário de Andrade. In: ANDRADE, Mário de. Mário de Andrade: fotógrafo e turista aprendiz. São Paulo: Instituto de Estudos Brasileiros, 1993. p.121-124. (HF)

PAVAN, Margot. Fotomontagem e pintura pré-rafaelista. In: FABRIS, Annateresa, org. Fotografia: usos e funçôes no século XIX. São Paulo: Edusp, 1991, p.233-259. (HF)

PEREGRINO, Nadja, org. Identidade: do análogo ao digital. s.l.: s.e., 1992. 30p. (Catálogo de exposição) (SH)

O Cruzeiro: a revolução da fotorreportagem. Rio de Janeiro: Dazibao/Agil, 1991. 109p. Originalmente Dissertação (Mestrado). (HF)

PEREGRINO, Nadja; OURIQUES, Evandro; VASQUEZ, Pedro, orgs. José Oiticica Filbo: a ruptura da fotografia nos anos 50. Rio de Janeiro: Funarte, 1982. (RD)

PESSANHA, Maria Edith de Araújo. A estereoscopia: o mundo em terceira dimensão. Rio de Janeiro: M.E.A. Pessanha, 1991. (HF)

PONCE DE LEON, Fernando. A experiência da Fundação Joaquim Nabuco. In: MUSEU DA IMAGEM E DO SOM. I Encontro de Fotografia e Memória Nacional. São Paulo, Secretaria da Cultura, 1981, p.33-35. (PT)

. Um depoimento sobre a coleção. In O retrato brasileiro: fotografias da Coleção Francisco Rodrigues 1840-1920. Rio de Janeiro: Funarte/Fundação Joaquim Nabuco, 1983. p.11-13. (RD)

PONTES, José Alfredo Otero Vidigal; TOLEDO, Benedito Lima de. São Paulo: registros 18991940. São Paulo: Eletropaulo, 1982. Apresentado como reedição de A cidade da Light: 18991930 (1982). (RD)

PREFEITURA DA CIDADE DO RIO DE JANEIRO. Fotografias do Rio de Ontem por Augusto Malta. Rio de Janeiro: Imprensa Nacional, 1978. (Coleção Memória do Rio, 7). (RD)

PROTTI, Antônio Davo. A fotografia no ABC. Comunicação e Sociedade. São Bernardo do Campo, v.5, n.10, p.50-57, dez. 1983. Fonte: Universidade Federal do Rio de Janeiro/Escola de Comunicações.

PUMAR, Sônia; TABET, Sérgio. O Rio de Janeiro em antigos cartões postais. Rio de Janeiro: Edição do Autor, 1985, 227p. (HF) 
RAMOS, Fernão. Indicialidade e narratividade na constituição da imagem-câmera. Imagens, Campinas, n.1, p.62-65, mar 1994. (TM)

RAUH, Rachel Cavalcanti. Blumenau em imagens: fotógrafos e fotografia como fonte do estudo da história da colônia de Blumenau (1850-1930). Santa Catarina, 1992. Dissertação (Mestrado) - Universidade Federal Santa Catarina. (SH)

REIS FILHO, Nestor Goulart. Aspectos da bistória da engenbaria civil em São Paulo: 1860-1960. São Paulo: CBPO/Kosmos, 1989. (RD)

RIBEIRO, Milton Roberto Monteiro. Linguagem fotográfica e informação. Brasília, 1991. Dissertação (Mestrado) - Departamento de Comunicação, Universidade de Brasília. (TM)

RIBEIRO, Suzana Barretto. Italianos do Brás: imagens e memórias: 1920-1930. São Paulo, Brasiliense/Pirelli, 1994. 162p. Originalmente Dissertação (Mestrado) (SH, tm)

ROBERTO, Hélio; CIMA, Marcelo Del; ROBERTO, Yolanda. Celebridades e mitos - o mundo do teatro em antigos cartôes postais. Rio de Janeiro: Yolanda Roberto Marketing \& Projetos Culturais Ltda, 1989. 84p. (Catálogo de exposição) (RD, hf)

ROBERTO, Yolanda. Os anos dourados do cartão-postal. Rio de Janeiro: Itanhangá Golf Club, 1988, 59p. (Catálogo de exposição) (RD, hf)

Trinta anos de Rio de Janeiro no cartão postal (1900-1930). Rio de Janeiro: Fundação Casa Rui Barbosa/ Gráfica Portinho Cavalcanti, 1982. (Catálogo de exposição) (RD) Fonte: MIRANDA, Victorino Coutinho Chermont de. A memória paraense no cartão postal (1900-1930). Rio de Janeiro, Ed. Liney, 1986. 156p.

ROCHA, Silvia Pimenta Velloso. A imagem inocente: investigação sobre o conceito de imagem como objeto singular. Rio de Janeiro, 1991. Dissertação (Mestrado) - Centro de Filosofia e Ciências Humanas, Universidade Federal do Rio de Janeiro. (TM)

RUBIN, Antônio Albino Canelas. Imagens no/do mundo contemporâneo. Revista Brasileira de Comunicaçâo. São Paulo, Intercon, ano XIV, n.64, p.108-111, jan.-jun. 1991. Fonte: ALVARENGA, Alexandre Curtiss. O mundo todo nos detalhes do cotidiano: aspectos teóricos da gênese e da significação na fotografia documentária. 2v. Campinas, 1994. Dissertação (Mestrado) - Instituto de Artes, UNICAMP.

SAHM, Estela. Fotografia E Desenho: Possíveis relações. In: FOTO a experiência alemã dos anos 50 GRAFIA . São Paulo: AS Studio, 1995. (Catálogo de exposição) (HF, rd)

SAIA, Luís TRINDADE, Jaelson Britan. São Luís do Paraitinga: levantamento métrico-arquitetônico fotográfico e estudos da formação de uma cidade.... São Paulo: Condephaat, 1977. (RD, hf)

SAMAIN, Etienne G. Entre a arte, a ciência e o delírio: a fotografia médica francesa na segunda metade do século XIX. Boletim do Centro de Memória da Unicamp, Campinas, v.5, n.10, p.11-32, jul.-dez. 1993. (SH) 
SAMAIN, Etienne. A caverna obscura: topografias da fotografia. Imagem, Campinas, n.1, p. 50-61, mar. 1994. (HF)

A fotografia tentacular: subsídios para uma arte de ver e de pensar. In: PAIVA, Joaquim, org. A fotografia brasileira. Brasília: s.c.p., s.d. (no prelo) (TM, hf)

SANTAELLA, Lúcia. Imagem pré-fotográfica-pós.Imagens, Campinas, n.3, p.34, dez. 1994. (TM)

SANTILLI, Marcos. Madeira-Mamoré: imagem \& memória. 1.ed. São Paulo: Empresa Villares, 1987. (2.ed. em 1988 pela Memória Discos e Edições) (RD)

SANTO ANDRÉ: cidade e imagens. Santo André: Prefeitura Municipal de Santo André, 1992. 143p. (RD)

SANTOS, N. P. Teixeira dos. A fotografia e o direito do autor. São Paulo: LTr, 1977. 151p. (HF)

SANTOS, Paulo. Arquitetura e urbanismo na Avenida Central. In: REGISTRO fotográfico de Marc Ferrez da construção da Av. Rio Branco, 1903-1906. Rio de Janeiro: Museu Nacional de Belas Artes, 1982, p.12. (Catálogo de exposição). (HF)

SANTOS. São Paulo: Mundo Impresso/Construtora Passareli, 1991: 128p. (RD)

SÃO PAULO antigo, São Paulo moderno: álbum comparativo. fotografias representativas de várias épocas da cidade de São paulo que assinalam os contrastes de seu impressionante progresso. São Paulo: Melhoramentos, 1953. (RD)

SÃO PAULO. Paulicéias perdidas. São Paulo: DPH, 1991. (RD)

SÃO PAULO. São Paulo em três tempos: álbum comparativo da cidade de São Paulo (1862-18871914). São Paulo: IMESP, 1982. (RD)

SÃO PAULO: 1968 a 1993. São Paulo: Empresa Das Artes/Transvalor, 1993. 108p. (RD)

SCAVONE, Rubens Teixeira. Da fotografia e da pintura. Foto-Cine Boletim. São Paulo, ano X, n.115, p.6-8, jan.-fev. 1960. (HF)

SEGATTO, José Antônio; PAUlo NETTO, José; RAMOS NETTO, José. PCB: memória fotográfica, 1922-1982. São Paulo: Brasiliense, 1982. 175p. (RD)

SENAC-PROJETO TIRADENTES. Um século de fotografia em Tiradentes. Tiradentes/MG: s.e., s.d. (HF) Fonte: FUNARTE. Fotografia: Levantamento Bibliográfico. Rio de Janeiro, Funarte, 1981. 70p. (Série Bibliografia, 35).

SERRANO, Eneida. Álbum de photographia. Porto Alegre: Museu de Comunicação Social Hipólito José da Costa, s.d. (Catálogo de exposição). (RD, hf)

SERVIÇO NACIONAL DE APRENDIZAGEM INDUSTRIAL/SÃO PAULO. O visual do rabalho: organização e preservação de fotografias no SENAI/SP. São Paulo: SENAIDepartamento Regional de São Paulo, 1995. 36p. (Núcleo Memória) (PT) 
SILVA, Cássia Maria Mello da. O acervo fotográfico do CPDOC: arranjo e descrição. VI Congresso Brasileiro de Arquivologia, Rio de Janeiro, 13-18 abr. 1986. (ms) (PT)

SILVA, Marco A. Construção do saber histórico: historiadores e imagens. Revista de História, São Paulo, 125-126, p.117-134, ago.jul. 199/2. (TM)

SILVA, Moacir. Ainda os cartões postais. Revista Postal Brasileira, Rio de Janeiro, out 1923. (HF). O cartão postal. Revista Postal Brasileira. Rio de Janeiro, set 1920. (HF).

SIMONE, Célia Camargo de. A experiência do Cpdoc. In: MUSEU DA IMAGEM E DO SOM. I Encontro de Fotografia e Memória Nacional. São Paulo: Secretaria da Cultura, 1981, p.57-73. (PT)

SIMSON, Olga R. de Moraes von. Brancos e negros no carnaval popular paulistano: 1914-1988. São Paulo, 1989. Tese (Doutorado) - Faculdade de Filosofia, Letras e Ciências Humanas, Universidade de São Paulo. (SH, tm)

Depoimento oral e fotográfico na reconstrução da memória histórico-sociológica: reflexões de pesquisa. Boletim do Centro de Memória UNICAMP, Campinas, v.3, n.5, p.14-24, jan.-jun., 1991. (TM)

SIMSON, Olga R. de Moraes von; LEITE, Miriam L. Moreira. Imagens do camaval: São Paulo, século XX. CERU/ANPOCS/FORD, Relatórios de pesquisa, n.1-2, fev. e set. 1985. (ms) (RD). Fonte: Bibliografia Temática. Boletim do Centro de Memória da UNICAMP, Campinas, v.5, n.10, jul.-dez. 1993, p.131-142.

SMIT, Johanna. Análise da imagem: um primeiro plano. In: SMIT, Johanna V., org. Análise documentária: análise da síntese. Brasília, MCT/CNPq/ IBICT, 1987, p. 99-111. (TM)

SOARES, Emmanuel de Macedo. Da fotografia e dos fotográfos em Niterói. Niterói: Manuscrito, 1991. (HF)

SOARES, Pedro Paulo. A dama branca e suas faces: a representação iconográfica da tuberculose. Manguinhos. História, Ciências, Saúde, Rio de Janeiro, v.1, n.1, p. 127-134, jul.-out. 1994. (SH)

SODRÉ, Muniz. À sombra do retrato. In: AZEVEDO, Paulo Cesar de; LISSOVSKY, Maurício, org. Escravos brasileiros do século XLX na fotografia de Cbristiano Jr. São Paulo: Ex-Libris, 1988, p.17-21. (SH)

SOUZA, Marisa de Oliveira. O Brasil através da imagem. Rio de Janeiro, 1991. 67p. Dissertação (Mestrado) - Centro de Filosofia e Ciências Humanas, Universidade Federal do Rio de Janeiro. $(\mathrm{SH}, \mathrm{tm})$ 
TEIXEIRA, Cid; TEIXEIRA, Cydelmo; MARCONI, Rino. Memória fotográfica. In: A Grande Salvador. Salvador: Governo do Estado, 1978, cap.11. (RD) Fonte: FERREZ, Gilberto; MATTOSO, Kátia M. Queirós. Babia: velhas fotografias, 1858-1900. Rio de Janeiro: Kosmos, 1988.

TEIXEIRA, Evandro: Fotojornalismo. Rio de Janeiro: Jornal do Brasil, 1982. (RD)

THIELEN, Eduardo Vilela et al. A ciência a caminbo da noça: imagens das expedições cientificas do Instituto Oswaldo Cruz ao interior do Brasil entre 1911 e 1913. Rio de Janeiro: Casa de Oswaldo Cruz, 1991, v.XV. 154p. (RD)

THIELEN, Eduardo Vilela. Imagens da saúde do Brasil: a fotografia na institucionalização da saúde pública. São Paulo, 1992. Dissertação (Mestrado) - Pontifícia Universidade de São Paulo. (SH)

TOLEDO, Benedito L.; KOSSOY, Boris. São Paulo: álbum comparativo da Cidade de São Paulo. 1862-1887. São Paulo: s.e., 1981. (RD)

TOLEDO, Benedito Lima de. Álbum iconográfico da Avenida Paulista. São Paulo: Ex-Libris, 1987. (RD) Anbangabaú. São Paulo: FIESP, 1989. (RD)

TURAZZI, Maria Inez, org. Catete e arredores. Rio de Janeiro: Museu da República, s.d. (Flagrantes do passado, 1) (RD)

Rio, cidade cosmopolita. Rio de Janeiro: Museu da República, s.d. (Flagrantes do passado, 2) (RD)

TURAZZI, Maria Inez. Poses e trejeitos: a fotografia e as exposições universais na era dos espetáculos (1839-1889). Rio de Janeiro: Funarte/Rocco, 1995. (HF) . Imagens da cidade colonial nas imagens do século XIX: o Rio de Janeiro no Brazil Pittoresco. Acerno - Revista do Arquivo Nacional, Rio de Janeiro, v.6, n.1-2, p.87-98, jan.-dez. 1993. (SH)

UM CLIC na história: fotojornalismo em Campinas. Campinas: PUC-Campinas, 1991. (HF)

UM RIO EM 68. Rio de Janeiro: Departamento Geral de Documentação e Informação Cultural, 1988, 110p. (RD)

VASCONCELLOS, Maria da Penha C., org. Memórias da saúde pública: a fotografia como testemunha. Rio de Janeiro/São Paulo: Hucitec/Abrasco, 1995. (RD)

VASQUEZ, Pedro. Dom Pedro II e a fotografia no Brasil. Rio de Janeiro: Index/CIS - Companhia Internacional de Seguros/Roberto Marinho, 1985. 243p. (HF)

Fotografia: reflexos e reflexões. Porto Alegre: L\&PM, 1986. 112p. (HF, tm, sh)

Fotógrafos pioneiros no Rio de Janeiro. Rio de Janeiro: Dazibao, 1990. 120p. (HF) 
Aspectos da fotografia brasileira no século dezenove. Rio de Janeiro, MAM/Depto. de Fotografia, Vídeo \& Novas Tecnologias, 1987. 37p. (Catálogo de exposição) (HF)

Brazilian photography in the nineteenth century. Houston, MAM/Depto. de Fotografia, Video \& Novas Tecnologias, 1988. (Houston Foto Fest, february/march 1988 and Maxwell Museum of Antrophology - The University of New Mexico, Albuquerque, april/may 1988). (Catálogo de exposição). (HF)

. La photographie brésilienne au dix-neuvième siècle. Paris, MAM/Depto. de Fotografia, Vídeo \& Novas Tecnologias, 1986. (Catálogo de Exposição). (Mois de la Photo) (HF)

Marc Ferrez, fotógrafo da Marinha Imperial. In: COUTO, Ronaldo Graça, org. A Marinha por Marc Ferrez. Rio de Janeiro: Index/Verolme, 1986, p.23-37. (HF)

Mestres da fotografia do Brasil: Coleção Gilberto Ferrez. Rio de Janeiro: Centro Cultural Banco do Brasil, 1995. 276p. (HF, rd)

. Niterói e a fotografia: 1858-1958. Niterói: Projeto Editorial Niterói Livros/Funiarte, 1994. 151p. (RD)

O retrato brasileiro. Rio de Janeiro: Funarte/Núcleo de Fotografia, 1983. (Catálogo de exposição). (HF)

. Olha o'passarinho! uma pequena história do retrato. In O retrato brasileiro: fotografias da Coleção Francisco Rodrigues 1840-1920. Rio de Janeiro: Funarte/Fundação Joaquim Nabuco, 1983. p.27-34. (HF)

Polaroid - o domínio do imaginário. Polaroid - imagens instantâneas. Rio de Janeiro: Funarte, 1986. (Catálogo de exposição) (TM, hf)

. Reflexos e reflexões. Cadernos do MAM, Rio de Janeiro, n.1, p.19-25, dez. 1983. (SH, tm)

Três mestres da fotografia brasileira no século XIX. Acervo - Revista do Arquivo Nacional, Rio de Janeiro, v.6, n.1-2, p.3-12, jan.-dez. 1993. (HF)

VERGER, Pierre. Retratos da Babia: 1946 a 1952. Salvador: Corrupio, 1980. (RD)

. 50 Anos de Fotografia. Salvador: Corrupio, 1982. 274p. (RD)

Centro histórico de Salvador: 1946 a 1952. Salvador: Corrupio, 1989. (RD). Fonte: Livros. INFORMATIVO, Salvador, Fundação Pierre Verger, v.1, n.1, nov.1989.

VIEIRA, João Luiz. Foto de cena e chanchada: a eficácia do "star-system" no Brasil. Rio de Janeiro, 1977. 59p. Dissertação (Mestrado) - Centro de Filosofia e Ciências Humanas, Universidade Federal do Rio de Janeiro. (SH) 
VIRUEZ, Guilma Vidal; FERREZ, Helena. Tratamento técnico bibliogräfico, catalogação, classificação e indexaçâo de fotos. Rio de Janeiro: FUNARTE, 1985. Trabalho apresentado no Seminário sobre preservação e conservação de fotografia. Rio de Janeiro, RJ, mar. 1985. (PT)

VIRUEZ, Guilma. O arquivo fotográfico. CICLO de palestras sobre fotografia, 1. Rio de Janeiro: Sindicato dos Jornalistas Profissionais do Município do Rio de Janeiro, 1983, p.31-44. (PT)

WALDHEIM, Sophia Pretzel, org. Álbum comemorativo do primeiro centenário da cidade de Santos. Santos: s.e., 1939. (RD)

WEHRS, Carlos. Niterói: tema para colecionadores. Rio de Janeiro: Associação de Cartofilia(RJ)/Gráfica Portinho Cavalcanti Ltda, 1987. 96p. (RD, hf)

ZANETTI, Fernando Luiz Motta. Da fotografia como arte. São Paulo, 1992. 135p. Dissertação (Mestrado) - Comunicação e Semiótica, Pontifícia Universidade de São Paulo. (HF, tm)

ZÚÑIGA, Solange Sette G. de. Perfil institucional: Centro de Conservação e Preservação Fotográfica. Acervo - Revista do Arquivo Nacional, Rio de Janeiro, v.6, n.1-2, p.155-162, jan.-dez. 1993. (PT)

ARTIGOS DA REVISTA ÍRIS

A ÉPOCA Hasselblad. Iris, n.337, p.30-32, maio 1981. (História).

A FOTO de primeira página do jornal. Íris, n.387, p.40-47, out. 1985.

A FOTOGRAFIA como registro da História: qual o caminho?. Íris, n.328, p.31-34, jul. 1980. (Debate).

A FOTOGRAFIA e os fotógrafos no Brasil. Íris, nº. 294, p.26-37, 1976. (Depoimentos).

A FOTOGRAFIA estereoscópica. Íris, São Paulo, n.308, 1978.

A FOTOGRAFIA nas revistas de informação. Íris, n⿳o.319, p.36-40, set. 1979.

A LEITURA da imagem no encontro Barthes com Emile. Íris, n.389, p. 8-10, dez. 1985.

AOS POUCOS a consagração como arte. Íris, Edição Especial, p.80-84, jan.-fev. 1987.

AS QUATRO damas do fotojornalismo. Íris, n.479, p.41-48, jan.fev. 1995.

BARROS, Mauro Rubens de. A descoberta isolada da fotografia no Brasil Iris, n. 336, p. 34, abr. 1981. (História).

BEILER, Berthold (Dr.). O poder da imagem. Iris, n.203, p.8-10, abr. 1969.

BIBLIOTECA Nacional: O nascimento da fotografia brasileira no valioso acervo da Biblioteca Nacional. Íris, n.488, p.38-48, nov. 1995. 
BLAU, Werner. A História da Leica. Íris, n.97, p.8-10, maio 1960.

BREVE História da "Zeiss.Ikon." İris, n.155, p.14-16, abr. 1965.

BRILL, Stefania; VASQUEZ, Pedro; MONTEIRO, Oswaldo. Balanço 81: fotografia brasileira descoberta pelo mundo. Iris, n.345, p.20-28, jan.-fev.1982.

. Museu da Fotografia. Íris. n.422, p.50-54, dez. 1989.

. Roteiro não turístico para um país transformado. Íris, n.350, p.21-24, jul. 1982.

A fotografia conquistando os jornais. Irris, Edição Especial, p.46-52, jan.- fev. 1987.

América Latina: a fotografia latino-americana via Zurique, Iris, n.347, p.20-25, abr. 1982.

Re-Toque fotográfico na instituição arte. Iris, n.352, p.20-22, set. 1982.

CARTÃO Postal. Iris, n.395, p.20-25.

CHAVES, Anesia Pacheco. A mulher retratada. Íris, n.348, p.5, maio 1982. (Fotopinião).

COMO organizar um banco de imagens inteligente. Íris, n.472, p.54-55, maio 1994.(Arquivo).

DOMÍClO Pinheiro. Íris, n.265, p.17-29, nov. 1974.

EXPOSIÇÕES: fotógrafos pioneiros do Brasil (1840-1920). Iris, n.310, p.8-9, nov. 1978.

EXPOSIÇÕES: um passeio pela cidade através da fotografia. Íris, n.315, p. 10, maio 1979.

FERNANDES JR., Rubens. O nu na fotografia: uma História de quase 150 anos. Íris, n.422, p.3740, jan.- fev. 1989.

_. Boa Perspectiva. Íris, n.423, p.52-54, mar. 1989.

ــ. Boca livre/Canudos, por Antônio Olavo. IRISFOTO, n.435, p.10, maio/jun.1990.

_. Fotografia. 150 anos de história e arte. Iris, n.428, ago. 1989.

_. O lado narcisístico da cidade. Irris, n.414, p.54-55, maio 1988.

FLUSSER, Vîlem. A distribuição de fotografias. Íris, n.370, p.36-37, maio 1984. Para uma filosofia da fotografia. Íris, n.366, p.3, dez. 1983. Preto e branco. Iris, n.354, p.28-32, nov. 1982. 
FOTOGRAFIA e autoritarismo. Íris, n.368, p.24-25, mar. 1984.

FOTOGRAFIA: a busca da linguagem brasileira. Iris, n.301, p.22-23, jan. 1978.

FOTOGRAFIA: imagem do homem ou da máquina?. Íris, n.365, p.24-26, nov. 1983.

FOTOGRAFIA: um acervo familiar. Íris, n.289, p.10, out. 1976.

FOTOJORNALISMO: um problema mal resolvido. Iris, n.372, p.36-38, jul. 1984.

HERCULES Florence. A fotografia foi descoberta no Brasil. Iris, n.278, p. 24, out. 1978.

HIPOLLITE Bayard. Íris. n.384, p.36-37, ago. 1985.

HOURS, Madeleine (Laboratório do Louvre). A fotografia cientifica e a História da Arte. Íris, n.162, p.48-54, nov. 1965 .

HUMBERTO, Luís. Fotografia e ideologia (ponto de vista). Íris, n.342, p.24, out. 1981.

Fotografia: procurando razôes. Îris, n.345, p.31-32, jan.fev. 1982. (Fotopinião).

ÍRIS, quarenta anos. Íris, edição especial, p.54-68, jan.- fev. 1987.

IZAR, Antônio. A fotografia - De Mo Tzu, há 250 anos A.C., até hoje. Íris, n.334, p.32-38, fev. 1981. (História).

KOSSOY, Boris. Algumas luzes sobre a polêmica História da Fotografia. Íris, n.373, p.13-18, ago. 1984 .

_. Hercules Florence, 150 anos. Íris, n.294, p.14-17, abr. 1976.

Militão de Azevedo e a fotografia documental do século XIX. Íris, n.311, p.12-13, dez. 1978.

. Pictorialismo e foto-amadorismo. Íris, n.310, p.10-11, nov. 1978. (Memória).

LEITE, Enio. A evolução social da fotografia. Íris, n.297, ago. 1977.

LIMA, Ivan. Os políticos nas fotografias e na História. Iris, n.356, p.14-15, jan.-fev. 1983. (Documento).

LUNARA: fotógrafo gaúcho do início do século. İris, n.324, p.32-39, mar. 1980.

MARIN, C. Aplicações da fotografia à filatelia (parte II). Íris, n.168, p.20-26, maio 1966.

Aplicações da fotografia à filatelia (parte I). Íris, n.167, p.28-33, abr. 1966. 
MEDINA, Cremilda. O caçador de velhas e preciosas imagens. Íris, n.323, p.38-39, jan.- fev. 1980. (Memória).

MINO CARTA e a edição de fotografia. Íris, n.304, p.42, maio 1978.

MONFORTE, Luiz. Atget, o fotógrafo de Paris. Iris, n.338, p.24-26, jun. 1981. (História)

NA PUBLICIDADE a fotografia não chegou aos quarenta. Iris, p.26-37, jan.-fev. 1987. (Edição Especial).

NEGROS fotógrafos. Íris. n.354, p.33-34, nov. 1982.

NETTO, Boaventura Cisotto. O microfilme na 2a. Guerra Mundial. Iris, n.150, nov. 1964.

NOGUEIRA, José. Marcos Magaldi (jornalista do Diário Grande ABC). Iris, n.316, p.14-23, jun. 1979.

O BRASIL antigo em 3.000 fotos. Íris, n.406, p.46-49, ago. 1987.

O MUSEU Brasileiro de fotografia já está em formação. Íris, n.337, p.35-38, maio 1981. (Exposição).

OLIVEIRA, Moracyr R. de. Boom da Fotografia. Iris, n.301, p.20, jan. 1978.

São Paulo sai às ruas. Íris, n.298, p.19-26, set. 1977.

A fotografia lembrando a História. Íris, n.303, p.9, abr. 1978.

Fotografia: um valor burguês. Íris, n.291, p.12-14, dez. 1976.

PEQUENA história de como tudo começou: a fotografia no cinema. Íris, n.376, p.24-37, nov. 1984.

PERSICHETTI, Simonetta. Para que nossa memória chegue colorida a nossos netos. Íris, n.337, p.16-18, maio 1981. (Preservação).

. Breve História do corpo nu. Íris, n.345, p.24-30, mar. 1982.

Dois álbuns resgatando nossa História. Íris, n.357, p.32-34, mar. 1983. (Livros).

Domício Pinheiro, 30 anos de fotojornalismo, 38 prêmios. Íris, n.325, p.26-30, abr. 1980.

Hildegard Rosenthal, Recordações de uma senhora fotógrafa. Íris. n. 345, p.16-18, jan.-fev. 1982. 
PETIT, Francisco. Fotografia na propaganda. Íris. n.291, p.34-37, dez. 1976.

PONTUAL, Roberto. No mesmo impasse 70 anos depois. Íris, n.347, p.32-34, abr. 1982. (Análise).

RETRATO sincero da fotografia. Íris, n.330, p.28, set. 1980. (Opinião).

RUTH Toledo. İris, n.313, p.14-25, mar. 1979.

SACHSE, Rolf. Na AGFA Foto-Historama, dois séculos de fotografia. Íris, n. 336, p.31-32, 1981.

(Exposição).

SERENO, Maria Zilda. Fotógrafas brasileiras. Íris. n.348, p.20-24, maio 1982.

SLOMP, Eda. Retrato: da aventura patética à obra de arte. Íris, n.379, p.48-50, mar. 1985.

STENGER, E. A História dos papéis fotográficos. Íris, n.98, p.8-10, jun. 1960. (Conclusão).

História dos papéis fotográficos. Íris, n.96, p. 4-7, abr. 1960.

STRELIAEV, Leonid. Liane Neves. Irisfoto, n.385, p.19-21, set.1985.

TEIXEIRA, Yeda S.S. De mulheres e fotógrafos: um pouco da História do nu no Brasil. Íris, n.422, p.33-34, jan.- fev. 1989.

TILLEUL, Pierre. A fotografia como arte. Iris, n.151, p.40, dez. 1964.

VALDEZ, Anibal. A História de um aparelho indestrutível (Leica). Íris, n.315, p.76-80, maio. 1979.

VASQUEZ; Pedro. A Funarte e a fotografia. Íris, n.335, p.30-35, mar. 1981. (Entrevista).

WALTER Firmo, 25 anos de fotografia-arte. İris, n.369, p.20-22, abr. 1984.

XAVIER, José. História da fotografia. Íris, n.283, p.14, abr. 1976.

\section{INSTITUIÇÕES}

Arquivo Nacional/RJ

Biblioteca Central da Pontifícia Universidade Católica de São Paulo

Biblioteca Central da Universidade Estadual de Campinas

Biblioteca Central da Universidade Federal Fluminense/RJ

Biblioteca de Pós-Graduação da Pontifícia Universidade Católica de São Paulo

Biblioteca Municipal Mário de AndradesP

Biblioteca Nacional-Coleção Geral/RJ

Biblioteca Nacional-Seção de Iconografia/RJ

Centro Cultural São Paulo 
Centro de Apoio à Pesquisa Histórica da Universidade de São Paulo

Centro de Memória da Universidade Estadual de Campinas/SP

Centro de Pesquisa e Documentação da História Contemporânea do Brasil da Fundação Getúlio Vargas/RJ

Escola de Comunicações da Universidade Federal do Rio de Janeiro

Escola de Comunicações e Artes da Universidade de São Paulo

Faculdade de Arquitetura e Urbanismo da Universidade de São Paulo

Faculdade de Filosofia e Ciências Sociais da Univemilade Estadual de Campinas/SP

Faculdade de Filosofia e Ciências Sociais da Universidade Federal do Rio de Janeiro

Faculdade de Filosofia, Letras e Ciências Humanas da Universidade de São Paulo

Fundação Nacional de Arte/RJ

Instituto Cultural Itaú/SP

Instituto de Artes da Universidade Estadual de Campinas/SP

Instituto de Estudos Brasileiros da Universidade de São Paulo

Instituto Joaquim Nabuco/PE

Museu de Arte Contemporânea da Universidade de São Paulo

Museu de Arte de São Paulo

Museu de Imagem e Som/SP

Museu Lasar Segall/SP

Museu Paulista da Universidade de São Paulo

Museu Republicano Convenção de Itu da Universidade de São Paulo 